\title{
EL SISTEMA DE FALLA NAVARRO: DESPLAZAMIENTOS IZQUIERDOS A LO LARGO DEL CINTURÓN DEFORMADO DEL CENTRO DE COSTA RICA
}

\author{
THE NAVARRO FAULT SYSTEM: LEFT-LATERAL DISPLACEMENTS \\ ALONG THE CENTRAL COSTA RICA DEFORMED BELT
}

Walter Montero ${ }^{1 *}$, Lepolt Linkimer $^{1,2}$ y Wilfredo Rojas ${ }^{1,2}$

${ }^{1}$ Centro de Investigaciones en Ciencias Geológicas

${ }^{2}$ Sección de Sismología, Vulcanología y Exploración Geofísica, Escuela Centroamericana de Geología, Universidad de Costa Rica y Red Sismológica

Nacional, Apdo. 214-2060, San Pedro, Costa Rica.

*Autor para contacto: wmonteropo@gmail.com

(Recibido: 17/11/2015; aceptado: 29/07/2016)

\begin{abstract}
In this study the Navarro Fault System is defined based on geologic, geomorphologic, and seismological observations. This fault system is located between the northern slopes of the Talamanca cordillera and the southern and southeastern slopes of the Irazu and Turrialba volcanoes and is characterized by left-lateral displacements. The Navarro fault system trends between east-west and northeast-southwest and includes the following fault segments: Tarrazu, Navarro, Cachi, Urasca, Paraiso, and Maravilla. There are two transtensional structures along the fault system: the step over Estrella and the Ujarras tectonic depression. Earthquakes during 1973-2015 were relocated illuminating the fault segments of the southwest portion of the system. The focal mechanisms calculated mainly correspond to strike-slip faults in agreement with morphotectonic observations.

Keywords: Morphotectonics, neotectonics, structural geology, seismicity, Costa Rica.

RESUMEN: En este estudio se define el Sistema de Falla Navarro con base en observaciones geológicas, geomorfológicas y sismológicas. Este sistema de falla está localizado entre las estribaciones norte de la cordillera de Talamanca y las faldas sur y sureste de los volcanes Irazú y Turrialba y está caracterizado principalmente por desplazamientos de tipo sinestral. El Sistema de Falla Navarro tiene un rumbo entre este-oeste y noreste-suroeste e incluye los segmentos denominados: Tarrazú, Navarro, Cachí, Urasca, Paraíso y Maravilla. Dos estructuras transtensivas denominadas Estrella y Ujarrás están presentes a lo largo del sistema de falla. Sismos en el periodo 1973-2015 fueron relocalizados iluminando las fallas del sector suroeste del sistema. Los mecanismos focales calculados corresponden en su mayoría con fallas de desplazamiento de rumbo en concordancia con las observaciones morfotectónicas.

Palabras clave: Morfotectónica, neotectónica, geología estructural, sismicidad, Costa Rica.
\end{abstract}




\section{INTRODUCCIÓN}

En la región central de Costa Rica, se ha definido el Cinturón Deformado del Centro de Costa Rica (CDCCR), que corresponde con una zona de deformación ancha caracterizada por fallas dextrales de rumbo NW a norte-sur y fallas sinestrales de rumbo este-oeste a ENE (Fig. 1; Marshall et al., 2000; Montero, 2001; Montero et al., 2013a). Los mecanismos focales obtenidos para sismos recientes concuerdan con las fallas neotectónicas cartografiadas (Montero \& Dewey, 1982; Fan et al., 1993; Fisher et al., 1994; Fernández, 1995; Fernández \& Pacheco, 1998; López, 1999; Quintero \& Güendel, 2000; Marshall et al., 2000; Montero, 2001). Dentro de las fallas sinestrales que se han reconocido en el CDCCR destacan las fallas Aguacaliente y Navarro (Fig. 1). La falla Aguacaliente ha sido objeto de varias investigaciones en los últimos años (Fernández \& Montero, 2002; Montero et al., 2005; Montero \& Kruse, 2006; Montero et al., 2013b; Henar et al., 2013). En contraste, la falla Navarro ha sido menos estudiada (p. e., Berrange, 1977; Aguilar, 1984; Salazar et al., 1992; GEOMATRIX CONSULTANTS, 1994; Sojo, 2015), a pesar de su cercanía a centros de población importantes y a la importante amenaza sísmica asociada.

El objetivo de este trabajo es presentar observaciones geológicas, geomorfológicas y sismológicas con el fin de identificar los diversos segmentos del Sistema de Falla Navarro, incluyendo dos relevos distensivos asociados: la zona de tracción Estrella y la depresión Ujarrás.

\section{MARCO TECTÓNICO}

La sismicidad y la tectónica activa de Costa Rica se relacionan con la interacción de varios bloques tectónicos dentro o cerca de su territorio (Fig. 1). Del lado pacífico, la placa del Coco se subduce bajo la placa Caribe. Dentro de esta última se reconoce el bloque del Antearco Centroamericano, el cual tiene un escape tectónico al NW, que es paralelo a la fosa Mesoamericana (LaFemina et al., 2009; Montero et al., 2013a) y con una tasa de movimiento de entre 8 a $11 \mathrm{~mm} /$ año (Fig. 1; LaFemina et al., 2009; Feng et al., 2012).
La batimetría de la placa del Coco que se subduce bajo Costa Rica varía a lo largo de diferentes sectores de su margen pacífico y ha ido cambiando a través de los últimos $12 \mathrm{Ma}$ (MacMillan et al., 2004). Al sur de Costa Rica, el levantamiento oceánico del Coco está siendo acarreado hacia la fosa Mesoamericana, desde hace unos 2-3 Ma (Fig. 1; MacMillan et al., 2004; Morell et al., 2012), provocando una indentación tectónica que ha afectado desde el pacífico sur hasta el sector Caribe de Costa Rica (Wells et al., 1988; Kolarsky et al., 1995; Collins et al., 1995; Suárez et al., 1995; Morell et al., 2012).

En la región central de Costa Rica, se ha definido el CDCCR, como una zona de deformación ancha, donde predominan fallas de desplazamiento dextral, con rumbos entre norte-sur a NW, fallas sinestrales este-oeste a ENE y fallas inversas este-oeste a WNW (Fig. 1; Marshall et al., 2000; Montero, 2001; Montero et al., 2013a). Asimismo, del lado NE de la cordillera de Talamanca y el Caribe del país, se localiza el Cinturón Deformado del Norte de Panamá (CDNP, Fig. 1), caracterizado por fallas inversas y pliegues con rumbo predominante NW.

Dentro de la placa cabalgante, el CDCCR se ubica del lado NW de la zona indentada por el levantamiento del Coco (Fisher et al. 1994, 1998; Marshall et al., 2000; Montero, 2001; Montero et al., 2013a). El CDCCR se considera el borde trasero del bloque del Antearco Centroamericano (Montero et al., 2013a). Una de las principales fallas sinestrales que han sido identificadas dentro del CDCCR, es el Sistema de Falla Navarro, el cual se ubica en su sector central-este. El mismo se inicia al oeste dentro del flanco norte de la cordillera de Talamanca, atravieza el sector este del valle Central y se continua al este sobre el flanco sur y SE de la cordillera volcánica Central (Fig. 1).

La geología de la cordillera de Talamanca atestigua la presencia de varios arcos volcánicos antiguos, incluyendo uno inicial de edad Paleoceno-Eoceno Temprano y otro intermedio ubicado en el Oligoceno Medio (de Boer et al., 1995). El evento volcánico más reciente en el eje principal de la cordillera de Talamanca y del lado $\mathrm{NE}$ de la zona de colisión del levantamiento del Coco, terminó en el Mioceno Tardío (antes de 5-8 


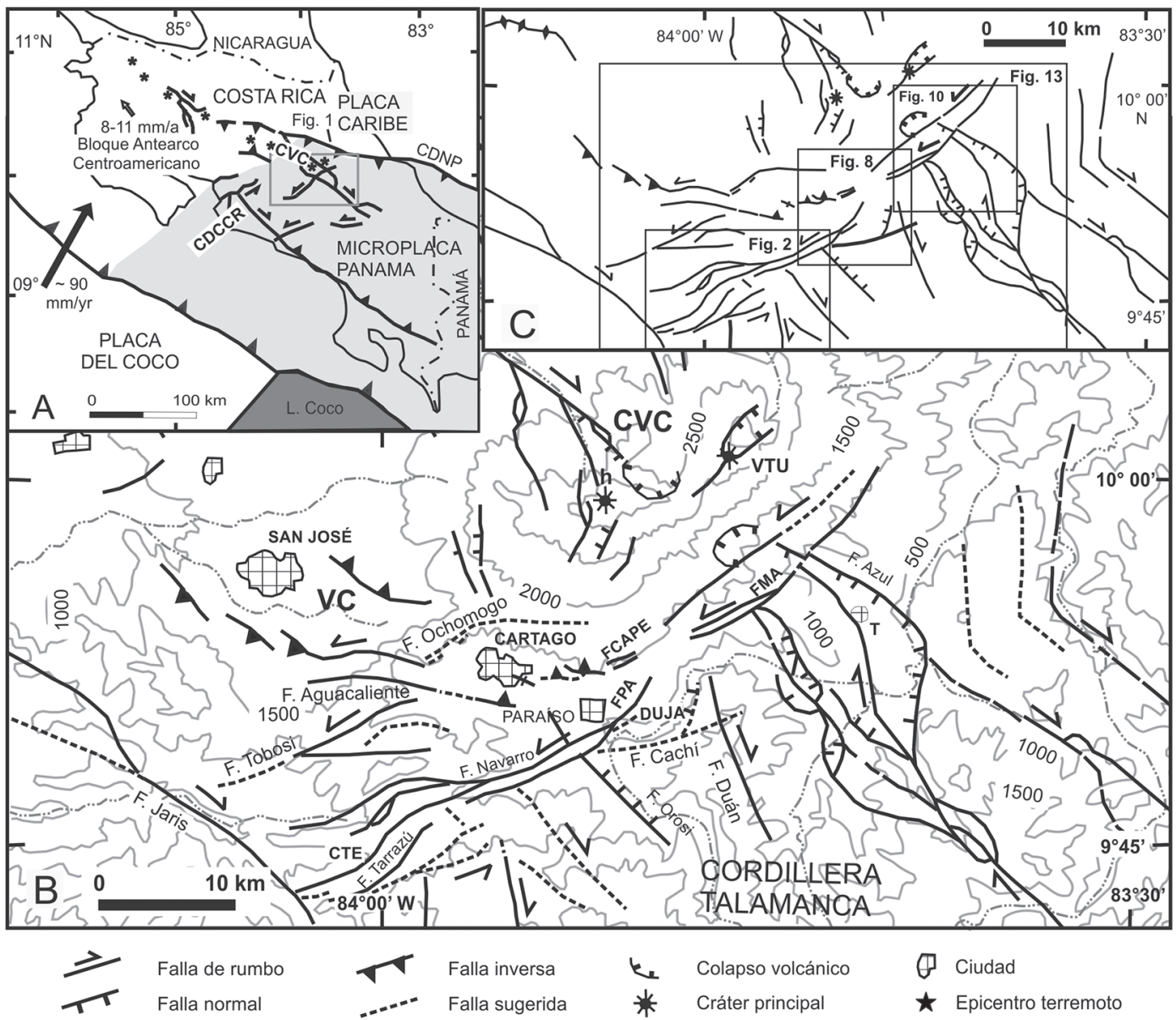

Fig. 1A: Mapa del contexto tectónico regional de Costa Rica. Se muestra el Cinturón Deformado del Centro de Costa Rica (CDCCR) y el Cinturón Deformado del Norte de Panamá (CDNP). La flecha rellena en negro muestra la velocidad relativa entre las placas del Coco y Caribe y la flecha sin rellenar corresponde con la velocidad obtenida por Norabuena et al. (2004) y Feng et al. (2012) para el bloque del Antearco Centroamericano. El rectángulo gris muestra el área que cubre la Fig. 1B. CVC es la Cordillera Volcánica Central. B: Mapa muestra el sistema de falla Navarro y otras fallas localizadas dentro del sector central-este del CDCCR. VC, CTE y DUJA, son respectivamente el Valle Central, la cuenca de tracción Estrella y la depresión tectónica Ujarrás. FPA, FCAPE y FMA son respectivamente las fallas Paraíso, Capellades y Maravilla, h y VTU son respectivamente los volcanes Irazú y Turrialba. C. Mapa de ubicación de las áreas que cubren las Figs. 2, 8, 10 y 13.

Ma; Morrell et al., 2012). Sin embargo, sobre las estribaciones norte de la cordillera de Talamanca persistió un vulcanismo durante el PliocenoPleistoceno Superior. Estas intrusiones y productos volcánicos se inyectaron entre sedimentos de diferentes ambientes o se depositaron sobre estos en diferentes sectores de la cordillera. Por otro lado, la cordillera volcánica Central se formó entre el Pleistoceno Superior y el Holoceno (Marshall et al., 2003; Alvarado \& Gans, 2012). El Valle Central quedó atrapado entre la cordillera volcánica
Central y el eje volcánico inactivo del lado norte de la cordillera de Talamanca (Marshall et al., 2003).

\section{ESTUDIOS PREVIOS}

La falla Navarro aparece por primera vez en la literatura geológica costarricense en el mapa geológico de Dóndoli \& Chaves (1968). Berrangé (1977) en un cartografiado geológico del SE del valle Central y norte de la cordillera de Talamanca 
muestran y caracterizan a la falla Navarro. Aguilar (1984) realiza un cartografiado geológico del sector oeste de falla Navarro y estudia la sismicidad de la zona con énfasis en los enjambres de temblores ocurridos en diciembre de 1977 y en setiembre de 1980. Denyer \& Montero (1988) extienden el trazo de la falla Navarro hacia el oeste hasta cerca de la falla Jaris.

Salazar et al. (1992) proponen que la falla Navarro combina movimiento sinestral con levantamiento en el bloque sur. Woodward \& Clyde (1993) identifican y definen las diversas características morfotectónicas de las fallas Navarro, Río Gato y Maravilla, las cuales de acuerdo con nuestra interpretación forman parte del Sistema de Falla Navarro. En GEOMATRIX CONSULTANTS (1994) se describe la morfología tectónica de la falla Navarro, se definen las zonas transtensivas Estrella y Ujarrás (ver siguiente sección) y se realizaron por primera vez estudios de trincheras a lo largo de la falla determinándose en una de ellas que la falla desplaza depósitos del Pleistoceno Superior-Holoceno. Montero (1994) incluyó la falla Navarro dentro del sistema de fallamiento neotectónico sinestral de Costa Rica. Montero et al. (1998) describen diversas características estructurales de la falla Navarro. Marshall et al. (2000) y Montero (2001) ubican esta falla dentro del sistema de fallas activas del CDCCR. En este último trabajo se extiende por primera vez el trazo de la falla sobre el borde sur y este del macizo volcánico Irazú-Turrialba. Linkimer (2003) describe nuevos segmentos del Sistema de Falla Navarro sobre los flancos sur y sureste de los volcanes Irazú y Turrialba. Henar et al. (2013) muestran las fallas Navarro y Maravilla y definen las magnitudes máximas que se les pueden asociar. Sojo (2015) realiza un levantamiento geológico de la hoja Tapantí del Instituto Geográfico Nacional, donde muestra la falla Navarro con una doble traza a lo largo del valle del río Navarro y continuándola al noreste del mismo. Finalmente, diversos autores han sugerido que la falla Navarro está sísmicamente activa y que algunos terremotos históricos se pueden relacionar con la misma (Salazar et al., 1992; GEOMATRIX CONSULTANTS, 1994; Montero et al., 1998; Linkimer, 2003).

\section{EL SISTEMA DE FALLA NAVARRO}

Se define el sistema de falla sinestral Navarro como un conjunto de fallas interconectadas cuyos principales segmentos de falla y estructuras tectónicas son de suroeste a noreste (Fig. 1, Cuadro 1): la falla Tarrazú, la zona de tracción Estrella, la falla Navarro, la falla Cachí (denominada Río Gato en Woodward \& Clyde, 1993), la falla Paraíso, la falla Urasca, la depresión Ujarrás y la falla Maravilla (denominado con este nombre en Woodward \& Clyde, 1993). La longitud acumulada por los diversos segmentos es aproximadamente de $115 \mathrm{~km}$. A continuación se describen los diversos sectores del Sistema de Falla Navarro.

\section{La falla Tarrazú}

Esta falla incluye varias trazas con rumbo entre ENE a NE. Al oeste termina contra la falla dextral Jaris (Montero \& Rojas, 2014; Arias \& Denyer, 1991; Fig. 2). Las diversas trazas de la falla Tarrazú desvían la divisoria continental. Del lado oeste de la divisoria (en la vertiente pacífica) los diversos segmentos cruzan las estribaciones sur y norte del valle del río Tarrazú (Fig. 2). En el lado este de la divisoria (en la vertiente caribe) los segmentos de falla se continúan a lo largo de varias nacientes del río Estrella. Además, los diversos segmentos cortan a través de depósitos volcánicos del Plioceno-Pleistoceno Inferior de la Formación Grifo Alto (Arias \& Denyer, 1990; Denyer \& Arias, 1991; denominado Complejo Aguacate por Berrangé, 1977).

La falla Tarrazú se distingue por dos trazas de falla principales denominadas fallas Tarrazú Norte y Tarrazú Sur, aunque también se reconocen otros segmentos de longitud menor. La falla 


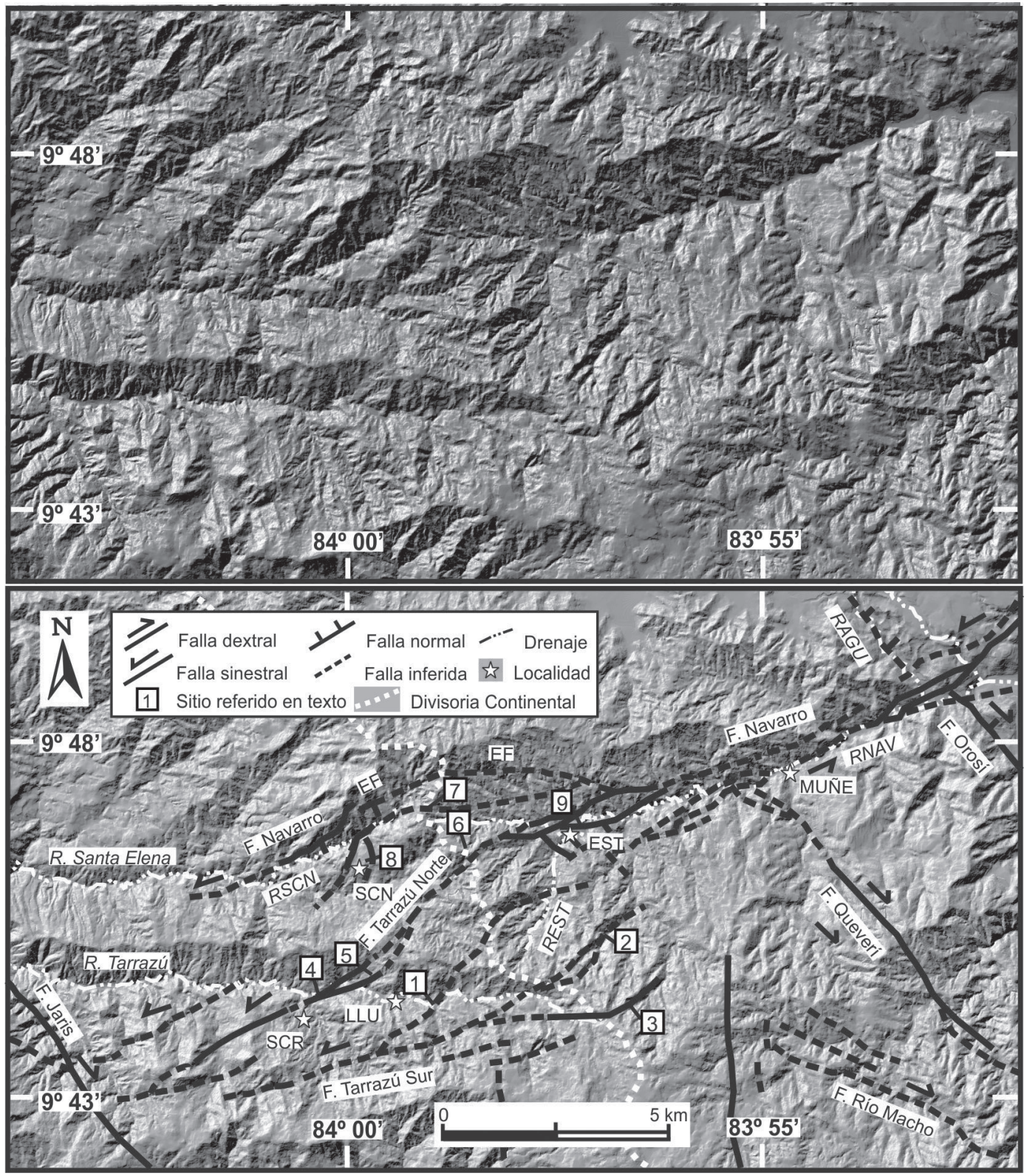

Fig. 2: Sector oeste del sistema de falla Navarro. A. Modelo de elevación digital del terreno (MED) sin interpretar. B. Interpretación de las fallas superpuestas sobre el MED. Obsérvese el desarrollo incipiente de la cuenca de tracción Estrella, ubicada entre la falla Tarrazú Sur y el sector oeste de la falla Navarro. La falla Tarrazú Norte corta la zona transtensiva transversalmente. Asimismo, la misma se ubica en una zona de divisoria continental. RSCN, REST, RNAV y RAGU son respectivamente los ríos San Cristóbal Norte, Estrella, Navarro y Aguacaliente. SCR, SCN, LLU, EST y MUÑE son respectivamente las localidades de Santa Cruz, San Cristóbal Norte, La Lucha, Estrella y Muñeco. EF es escarpe de falla. 
Cuadro 1

Segmentos del sistema de falla Navarro

\begin{tabular}{|c|c|c|c|}
\hline Nombre (longitud) & Rumbo & Expresión morfotectónica & $\begin{array}{c}\text { Grado de actividad y sismici- } \\
\text { dad asociada }\end{array}$ \\
\hline $\begin{array}{l}\text { Tarrazú }(37 \text { km). Incluye Tar- } \\
\text { razú Norte }(18 \mathrm{~km}) \text { y Tarrazú } \\
\text { Sur }(19 \mathrm{~km})\end{array}$ & $\begin{array}{l}\text { Aprox. } \mathrm{N} 60^{\circ}-70^{\circ} \mathrm{E} \text { con } \\
\text { trechos cortos con rumbos } \\
\text { entre } \mathrm{E}-\mathrm{W} \text { a N-S }\end{array}$ & $\begin{array}{l}\text { Moderada a prominente con } \\
\text { indicadores morfotectónicos } \\
\text { característicos de las fallas de } \\
\text { desplazamiento de rumbo }\end{array}$ & $\begin{array}{l}\text { Activa. Sismicidad durante } \\
1973-2015\end{array}$ \\
\hline Navarro (28 km) & De E-W a N65 $-75^{\circ} \mathrm{E}$ & $\begin{array}{l}\text { Moderada a prominente con } \\
\text { indicadores morfotectónicos } \\
\text { característicos de las fallas de } \\
\text { desplazamiento de rumbo }\end{array}$ & $\begin{array}{l}\text { Activa. Sismo del } 9 \text { de agosto } \\
1991 \text { (Mw 5,2) y posible- } \\
\text { mente } 22 \text { de agosto } 1951 \text { (Ms } \\
\text { 5,4). Además: sismicidad } \\
\text { durante 1973-2015 }\end{array}$ \\
\hline Cachí (13 km) & $\mathrm{N} 75^{\circ} \mathrm{E}$ & Débil a moderada & $\begin{array}{l}\text { Posiblemente inactiva sin } \\
\text { sismos asociados }\end{array}$ \\
\hline Paraíso (8 km) & $\mathrm{N} 40^{\circ} \mathrm{E}$ & $\begin{array}{l}\text { Moderada a prominente con } \\
\text { indicadores morfotectónicos } \\
\text { característicos de las fallas de } \\
\text { desplazamiento de rumbo }\end{array}$ & Activa sin sismos asociados \\
\hline Urasca (6 km) & $\mathrm{N}-\mathrm{S}$ & $\begin{array}{l}\text { Débil a moderada. Escarpe } \\
\text { de falla facetado al oeste } \\
\text { disectado }\end{array}$ & $\begin{array}{l}\text { Posiblemente inactiva sin } \\
\text { sismos asociados }\end{array}$ \\
\hline Maravilla (23 km) & $\mathrm{N} 45-50^{\circ} \mathrm{E}$ & $\begin{array}{l}\text { Moderada a prominente con } \\
\text { indicadores morfotectónicos } \\
\text { característicos de las fallas de } \\
\text { desplazamiento de rumbo }\end{array}$ & Activa sin sismos asociados \\
\hline
\end{tabular}

Tarrazú Sur, con una longitud de $\sim 19$ km, corresponde con al menos tres trazas que definen el límite sur de la zona de tracción Estrella (Figs. 1 y 2, Cuadro 1). El desvío izquierdo más importante que origina es el del río Tarrazú $(\sim 0,5 \mathrm{~km}$; sitio 1 en Fig. 2). Asimismo, se observan valles lineales y valles de falla (p. e. sitios 2 y 3 en Fig. 2), sillas de falla y desvíos izquierdos de divisorias de filas.

La falla Tarrazú Norte tiene una extensión de unos $18 \mathrm{~km}$ y al este se une con la falla Navarro cerca de la localidad de Estrella (Fig. 2, Cuadro 1). Esta traza de falla se puede considerar como una falla transversal a la depresión tectónica Estrella (cross-basin fault, McClay \& Dooley, 1995). Del lado oeste de la divisoria continental, la falla se caracteriza por valles lineales, sillas de falla, escarpes de falla facetados y desvíos de drenajes y divisorias (Fig. 3). El principal desvío izquierdo es el del río Tarrazú $(\sim 0,7 \mathrm{~km}$, sitio 4 en Fig. 2). Aguas arriba del desvío, se han depositado terrazas aluviales, sobre las cuales se ubica la localidad de La Lucha (LLU en Fig. 2). Sobre la margen norte del valle del río Tarrazú, la falla se divide en dos trazas entre las cuales se ha originado una zona deprimida, asociada con una transtensión local (sitio 5 en Fig. 2). Al cruzar la divisoria continental la falla muestra un desvío izquierdo de la misma (sitio 6 en Fig. 2).

\section{La zona de tracción Estrella}

Fue sugerida por primera vez en GEOMATRIX CONSULTANTS (1994). Corresponde con una estructura transtensiva, que se localiza entre la falla Tarrazú Sur y el sector oeste de la falla Navarro (Fig. 2), que está dentro de una zona montañosa con alturas superiores a los $2 \mathrm{~km}$ y donde hay una divisoria continental. La estructura transtensiva Estrella se ha formado por un relevo izquierdo entre los segmentos Tarrazú Sur y Navarro (ver adelante), traslapados 


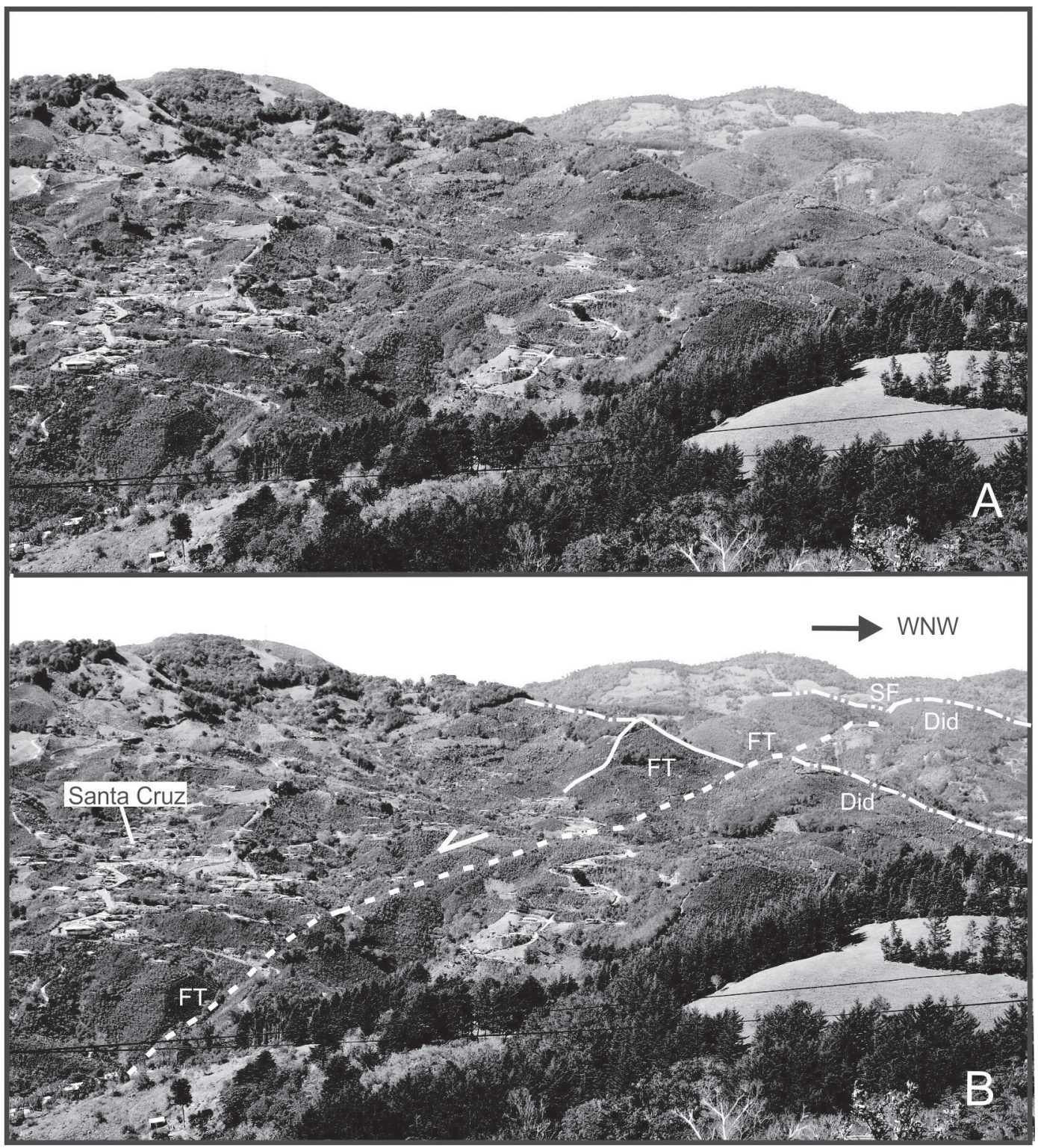

Fig. 3: Vista de la falla Tarrazú Norte cerca de la localidad de Santa Cruz (ubicación en Fig. 2). A: Foto sin interpretar. B: Interpretación de la traza de falla (línea discontinua gruesa) mostrando facetas triangulares (línea fina, FT), silla de falla (SF) y divisorias desviadas (Did; línea a trazo y punto).

y separados 5-7 km entre sí y con rumbos similares. La zona de tracción Estrella muestra un desarrollo incipiente, dado que no ha alcanzado a formar una cuenca con depositación aluvial significativa, lo que puede sugerir que esta estructura es relativamente reciente. Adicionalmente, la ubicación geográfica de esta estructura tectónica en una zona montañosa, donde se presenta una divisoria continental, no favorece el desarrollo de la estructura transtensiva, ya que los ríos principales que la drenan, como son el río Estrella y sus nacientes (lado caribe de la divisoria continental) y los ríos Santa Elena y Tarrazú y sus nacientes (lado pacífico de la divisoria), son de bajo caudal 
y drenan áreas pequeñas. Asimismo, al ser ríos de montaña, los sedimentos son rápidamente transportados fuera de la estructura transtensiva. Los únicos depósitos de terrazas aluviales observados en el campo son de carácter local, por ejemplo, los ubicados en el poblado Estrella y alrededores, en donde confluyen varias quebradas con el río Estrella y se intersectan diversas fallas con movimientos sinestral y dextral (Fig. 2). Tanto la tasa de actividad como la magnitud del desplazamiento normal de las fallas que controlan el desarrollo la estructura son actualmente desconocidas.

El límite norte de la estructura Estrella corresponde con el tramo oeste de la falla Navarro, que tiene un rumbo de entre $\mathrm{N} 50-60^{\circ} \mathrm{E}$ a esteoeste y un movimiento oblicuo de tipo sinestralnormal (Fig. 4). Al oeste, la falla Navarro pierde expresión morfotectónica al cruzar el río Santa Elena, unos $5 \mathrm{~km}$ al este de la falla Jaris (Montero \& Rojas, 2014). La componente normal de la falla Navarro se caracteriza por escarpes de falla facetados al sur, indicando que el lado sur se hunde a lo largo de fallas con componente normal (EF en Fig. 2). El escarpe más notorio se localiza del lado norte del río San Cristóbal Norte (EF en Figs. 2, 4 y $5 \mathrm{~A}$ ). Además, existen fallas con componente normal que se observan separando los depósitos volcánicos de la Formación Grifo Alto (sitio 7 en Fig. 2; Fig. 5B). GEOMATRIX CONSULTANTS (1994) igualmente reporta fallas con componente normal y de desplazamiento de rumbo dentro de la estructura Estrella. Del lado sur del río San Cristóbal Norte, dos trazas de la falla Navarro originan una transtensión local, en cuyo bloque descendido se asienta la población de San Cristóbal Norte (sitio 8 en Fig. 2; DTSCN en Fig. 4B). Esta estructura se identifica por dos escarpes de falla, uno facetado al oeste (lado este de la estructura) y el otro al este (lado oeste del graben).

Al cruzar al este de la divisoria continental, la falla Navarro tiene un rumbo este-oeste y movimiento oblicuo sinestral-normal (Fig. 2). La componente normal se refleja mediante un escarpe de falla (EF en Fig. 2), del cual se originan varias nacientes del río Estrella. Asimismo, la falla Navarro muestra desvíos izquierdos de drenajes.

Como se mencionó previamente, el límite sur de la zona transtensiva Estrella es la falla Tarrazú Sur. Sin embargo, este lado muestra escarpes de falla de menor altura y por tanto la componente vertical es menor que en el lado norte. Lo anterior sugiere una asimetría de la estructura, con mayor hundimiento en el lado norte. GEOMATRIX CONSULTANTS (1994) propuso que la componente de desplazamiento normal en las fallas de los bordes de la estructura Estrella tienen desplazamientos acumulados del orden de unas decenas de metros a un máximo de una a dos centenas de metros. Sin embargo, la geometría de las trazas mostradas por estos autores no concuerda con nuestra interpretación, especialmente en el sector sur, por lo que los anteriores valores deben ser reevaluados en un trabajo futuro más detallado.

La zona donde las fallas Tarrazú Norte, Tarrazú Sur y Navarro se unen para formar el ápice este de la zona de tracción Estrella, se caracteriza por trazas de falla atravesando las estribaciones montañosas al sur y norte y en el fondo de los valles de los ríos Estrella y Navarro (Figs. 2 y 6). Al NE del poblado Estrella, una de las trazas anteriores desvía a la izquierda una colina y al río Estrella. Aguas arriba del desvío se observan depósitos aluviales represados (sitio 9 en Fig. 2; Fig. 7A).

\section{La falla Navarro al este de la zona de tracción Estrella}

Al este del cierre de la zona de tracción Estrella y del poblado de Muñeco, la falla Navarro continúa sobre las estribaciones montañosas del lado norte y el fondo del valle del río Navarro. La falla está expresada por el desvío de drenajes y divisorias, sillas, trincheras y bermas de falla y escarpes locales facetados en contra y favor del drenaje.

Al oeste de la confluencia de los ríos Aguacaliente y Navarro, se encuentran depósitos de travertino, que atestiguan antiguas fuentes 


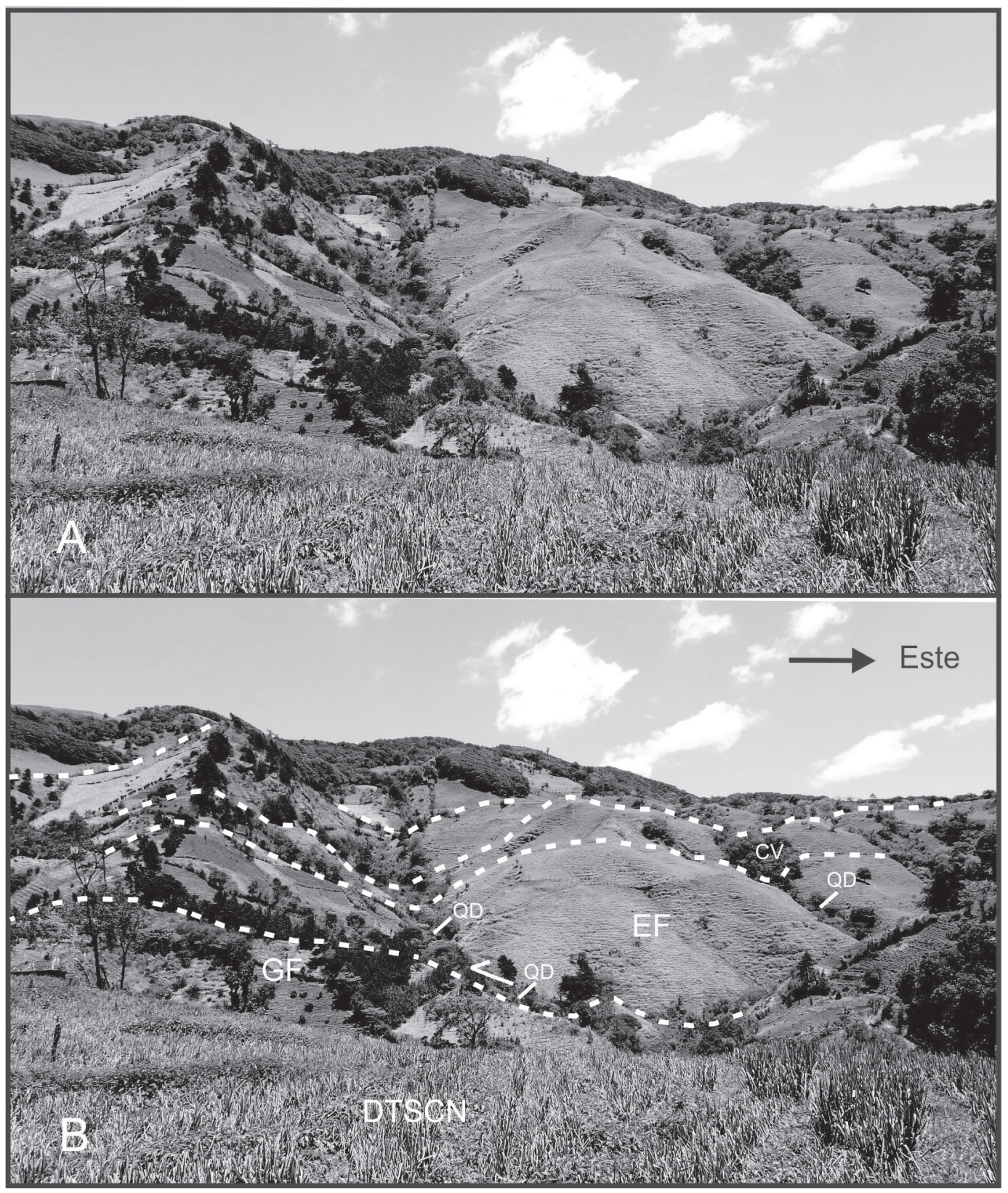

Fig. 4: Vista desde la localidad de San Cristóbal Norte de la falla Navarro, cuyas trazas levantan el lado norte del valle del río San Cristóbal Norte. A: Foto sin interpretación. B: Foto interpretada mostrando el movimiento sinestral-normal a lo largo de varias trazas de la falla (línea a trazos blancos). EF: escarpe de falla. GF: gancho de falla que desvía divisoria. QD: quebrada desviada a la izquierda. CV: estructura en copa de vino. DTSCN corresponde con la depresión tectónica de San Cristóbal Norte, en cuyo piso deprimido se asienta la localidad del mismo nombre (ver Fig. 2). 

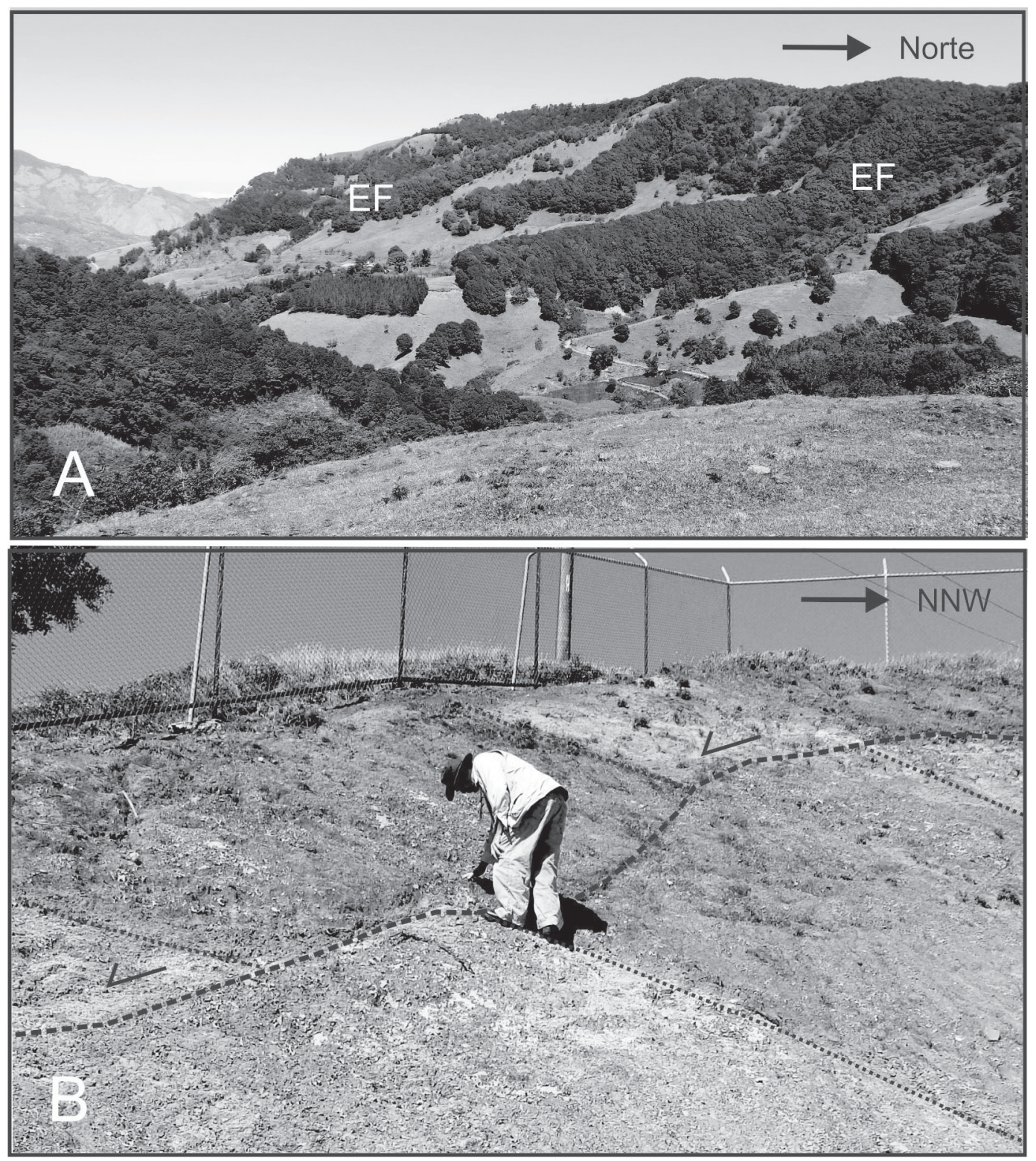

Fig. 5A: Vista del escarpe de la falla Navarro (EF) del lado norte del valle del río San Cristóbal Norte. B: Falla con separación normal (a trazos negros) afectando depósitos volcánicos de la Formación Grifo Alto (sitio 7 en Fig. 2). La separación de inclinación es de $1,5 \mathrm{~m}$. El rumbo de la falla es este-oeste y buza $35^{\circ}$ al sur.

termales sub-paralelas con la traza de falla (sitio 1 en Fig. 8). Asimismo, una traza origina un desvío izquierdo del río Aguacaliente (sitio 2 en Fig. 8). GEOMATRIX CONSULTANTS (1994) realizó un levantamiento de las terrazas a lo largo del río Navarro desde el oeste de la localidad de Muñeco hasta unos kilómetros aguas abajo de la confluencia del río Aguacaliente con el río Grande de Orosi, indicando que las terrazas no muestran cambios obvios en sus alturas.

Al salir del valle del río Navarro, la falla Navarro cambia de un rumbo $\mathrm{N} 65-75^{\circ} \mathrm{E}$ a un 


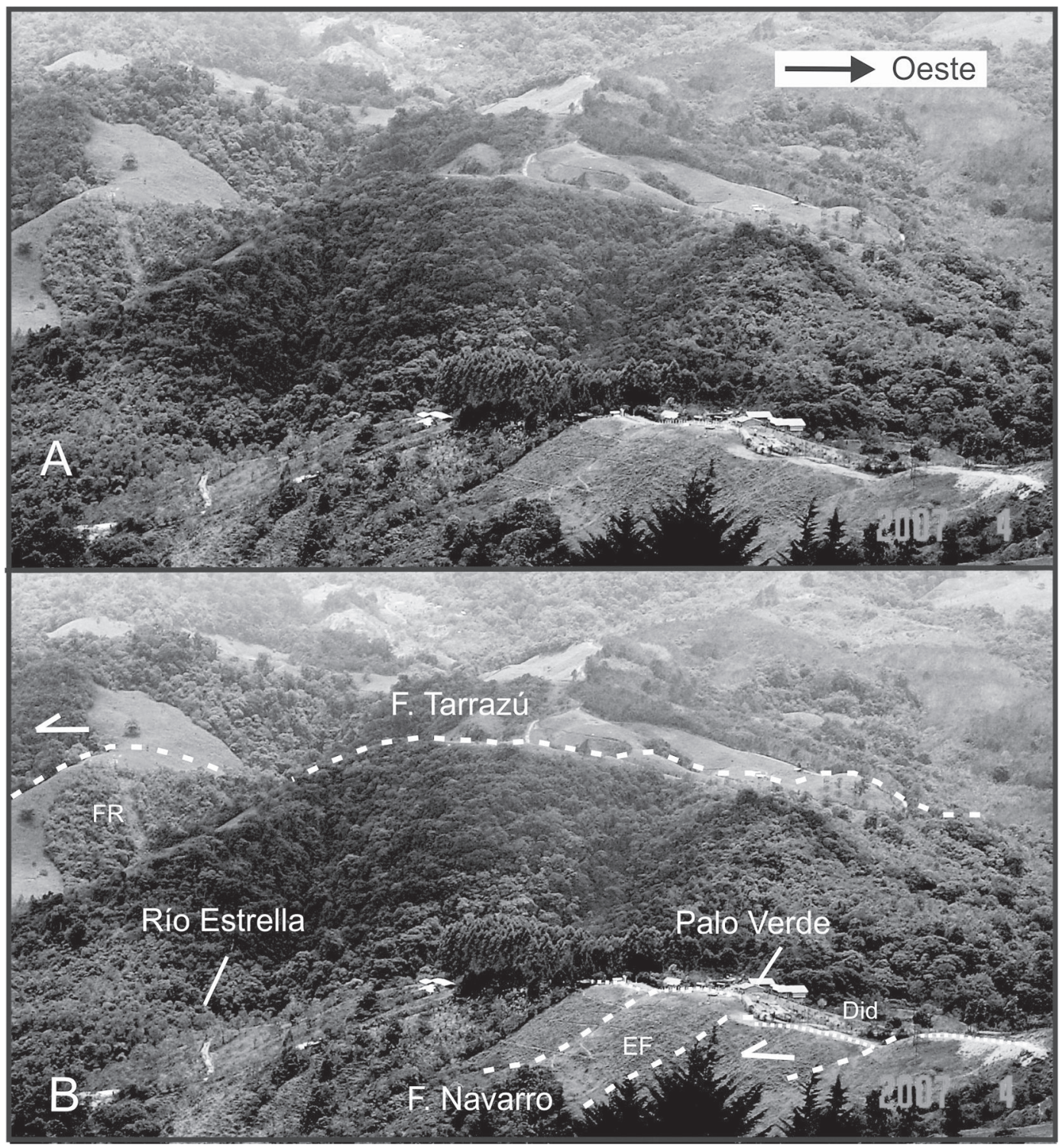

Fig. 6: Vista de las trazas de las fallas Tarrazú (lado sur del río Estrella) y Navarro (lado norte del río Estrella), las cuales convergen para formar el ápice este de la zona de tracción Estrella. A: Foto sin interpretar. B: Foto muestra las trazas de falla interpretadas como líneas discontinuas gruesas. En primer plano, las trazas de la falla Navarro desvían la divisoria (Did; línea de puntos blancos) de una estribación montañosa, donde se localiza el poblado de Palo Verde, originando escarpes de falla facetados al norte (EF). Al fondo una traza de la falla Tarrazú origina un desvío de una faceta rectangular (FR).

rumbo entre $\mathrm{N} 40-65^{\circ} \mathrm{E}$, y a partir de este cambio de rumbo se le denomina como falla Paraíso. La zona de cambio de rumbo incluye varias trazas de falla que suavizan este cambio de orientación y a su vez originan una transtensión local, la cual define el ápice oeste de la zona de depresión Ujarrás, donde afloran una serie de terrazas asociadas con la confluencia del río Aguacaliente con los ríos Navarro y Grande de Orosi (Fig. 8).

La falla Orosi, de rumbo NW, termina al sur de donde ocurre el cambio de rumbo entre las fallas Navarro y Paraíso (Figs. 2 y 8). La falla Orosi 


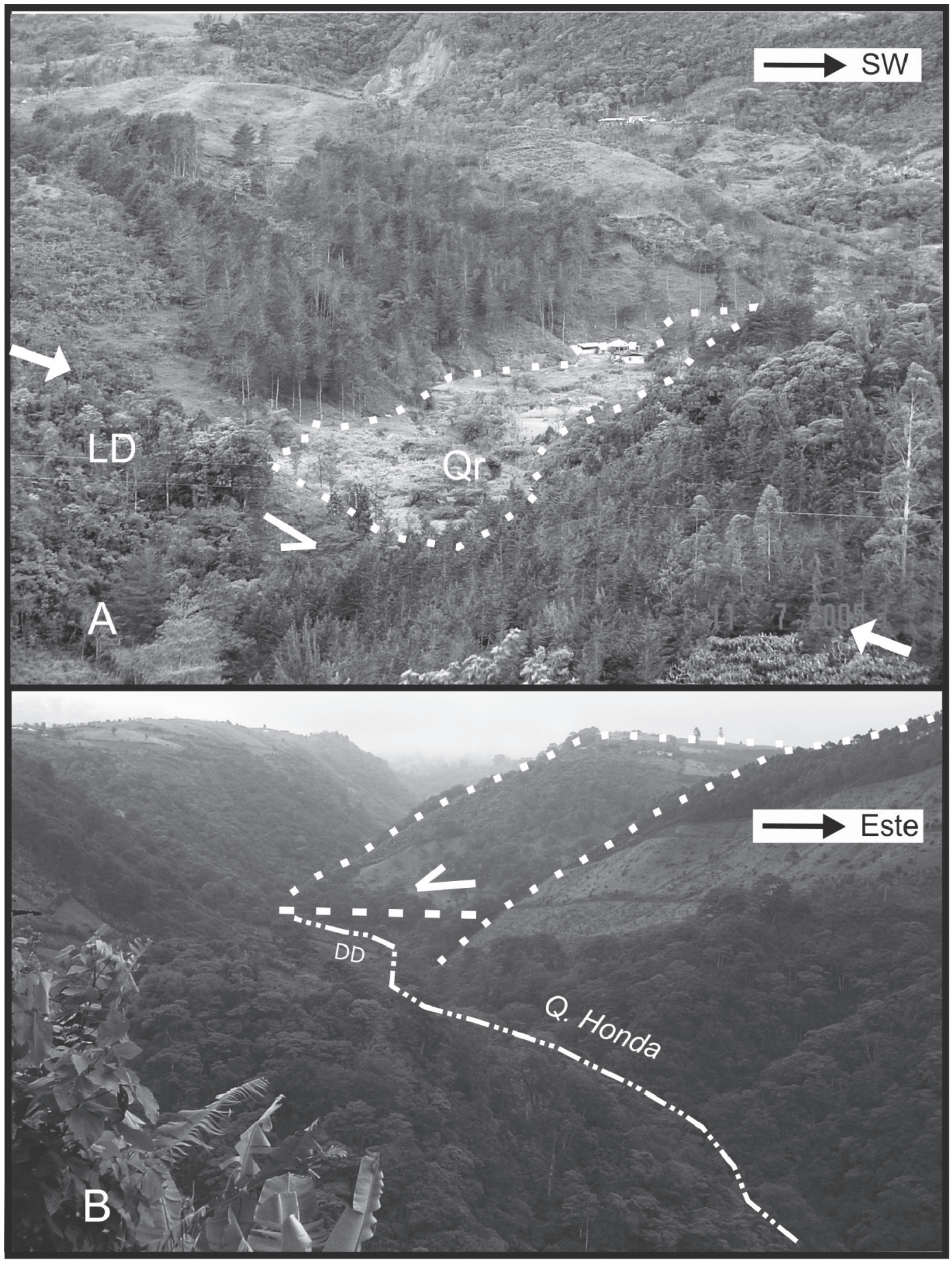

Fig. 7A: Vista de la falla Navarro (marcada por flechas rellenas en blanco), desplazando una loma (lomo de obturación, LD), la cual origina un depósito del Cuaternario represado (Qr) aguas arriba del río Estrella. B. Vista del desvío izquierdo del valle de la quebrada Honda (marcado con puntos blancos espaciados) asociado con la falla Maravilla (marcada como una línea gruesa discontinua). 


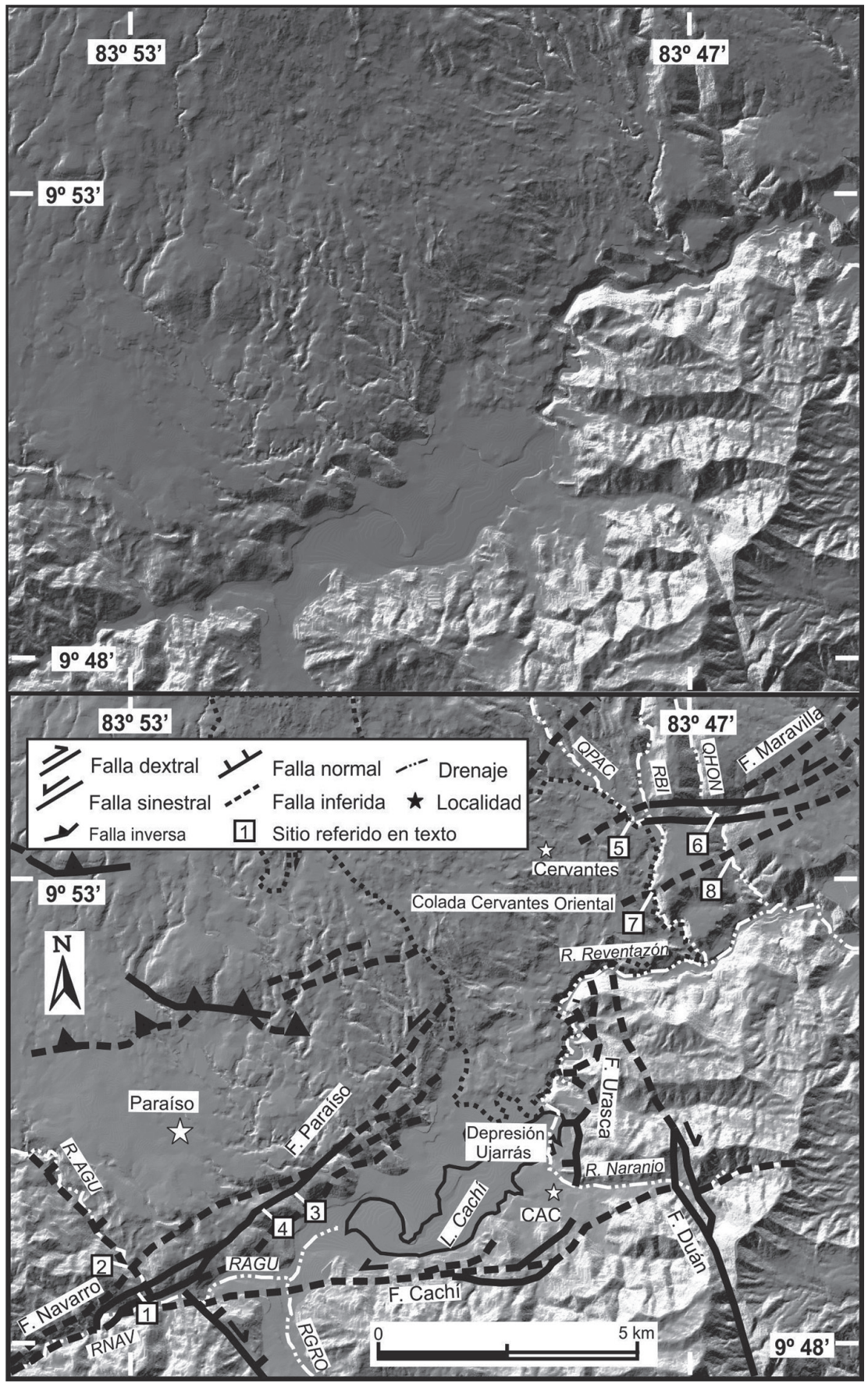

Fig. 8: Sector central del sistema de falla Navarro. A. Modelo de elevación digital del terreno (MED) sin interpretar. B. Interpretación de las fallas superpuestas sobre el MED. La depresión Ujarrás se relaciona con el relevo izquierdo entre las fallas Navarro-Cachí y Maravilla. RAGU, RGRO, RNAV, RBI, QPAC y QHON son respectivamente los ríos Aguacaliente, Grande de Orosi, Navarro y Birris y las quebradas Pacayas y Honda. La línea negra delgada marca el borde del lago Cachí. El borde externo de la colada de lava de Cervantes Oriental se identifica con una línea negra a puntos. 
se evidencia por un escarpe facetado al este, el cual sugiere una falla con una alta componente de desplazamiento normal. Sin embargo, esta falla también parece tener una componente de rumbo dextral (Denyer et al., 2003). Existe una posible continuación de la falla Orosi al norte de la falla Navarro a lo largo de una traza de falla inactiva, de rumbo NW y paralela al curso medio del río Aguacaliente, que habría levantado el lado oeste del valle de dicho río (Figs. 2 y 8). Esta posible traza de falla inactiva implicaría un desvío izquierdo de 0,9-1 km de la traza de la falla Orosi a ambos lados de la falla Navarro.

\section{Segmento de falla Paraíso}

Al SE de la ciudad de Paraíso, la falla Paraíso es la continuación de la falla Navarro al salir al este del valle del río Navarro (Figs. 1 y 8 , Cuadro 1). La falla muestra varias trazas con movimiento sinestral y en algunas también con una componente normal. La componente normal de algunas de las trazas de falla definen el borde oeste de la depresión Ujarrás, evidenciada por escarpes de falla facetados al este (Fig. 8), donde afloran las lavas del Miembro Paraíso de la Formación Reventado (Krushensky, 1972), de edad menor a 0,2 Ma (Denyer \& Alvarado, 2007).

La traza de la falla Paraíso se identifica por el desvío izquierdo de drenajes y divisorias, trincheras y sillas de falla y cambios de pendiente. Un desvío izquierdo con cambio de pendiente es el que da origen a la catarata llamada "el salto de los novios" (sitio 3 en Fig. 8). La traza de la falla está cubierta donde cruza la colada de Cervantes Oriental, de una edad cercana a los 17.000 años (Alvarado \& Vega, 2013; Fig. 8). No se han determinado evidencias de campo confiables que definan el trazo de falla dentro de esta unidad, dado su carácter blocoso o de escombros escoriáceos (Alvarado \& Vega, 2013).

Se considera que esta falla está activa dada su relación de continuidad con la falla Navarro, con actividad sísmica asociada (ver adelante). GEOMATRIX CONSULTANTS (1994) reporta los resultados de un estudio de trinchera realizado al sur de Paraíso, en el cual se determinó una zona de falla de al menos $50 \mathrm{~m}$ de ancho, cortando depósitos de rocas volcánicas y sedimentarias con edades estimadas entre 50.000 y 150.000 años (sitio 4 en Fig. 8).

\section{Las fallas Cachí y Urasca y la Depresión Ujarrás}

La falla Cachí con un rumbo entre $\mathrm{N} 60-75^{\circ} \mathrm{E}$ y un movimiento predominante sinestral, se inicia al oeste cerca de la unión del río Navarro con el río Aguacaliente y se extiende al este con un trazo bastante lineal hasta las nacientes del río Naranjo (Fig. 8). Tiene una longitud de unos 13 km (Cuadro 1). Berrangé (1977) la identifica como el sector este de la falla Navarro. Sin embargo, en este trabajo se considera como un segmento inactivo de la falla Navarro y por esto se prefiere distinguirla con el nombre de falla Cachí. Woodward \& Clyde (1993) la reconocieron como una falla sospechosa de ser activa y la denominaron falla Río Gato. Sin embargo, se desconoce la justificación de este nombre, por lo que se prefiere el nombre de falla Cachí, dado que su traza se localiza cerca de ese poblado (Fig. 8). GEOMATRIX CONSULTANTS (1994) la reconocen como el límite sur de una zona transtensiva y la identifican por los cambios en pendientes de las laderas que provoca. La falla Cachí limita el borde sur del valle superior del río Reventazón y del lago de Cachí, donde afloran rocas volcánicas del Terciario Superior, mientras que del lado norte del valle afloran rocas volcánicas del Pleistoceno, asociadas con el volcán Irazú (Krushensky, 1972; Berrangé, 1977; Denyer \& Alvarado, 2007). La falla Duán, de rumbo $\mathrm{N} 20^{\circ} \mathrm{W}$, desplaza unos 200 $\mathrm{m}$ en sentido dextral al extremo este de la falla Cachí, lo cual sugiere que esta última falla se encuentra inactiva (Fig. 8). En la zona donde ambas fallas se intersectan, la falla Duán presenta un relevo transtensivo, el cual ha sido rellenado por depósitos aluviales acarreados por varias nacientes del río Naranjo. Evidencia adicional de la inactividad de esta falla se reporta en GEOMATRIX CONSULTANTS (1994), donde se indica que ni en las fotografías aéreas ni en la inspección de 
campo se determinaron desplazamientos laterales o verticales que afecten las terrazas asociadas con la confluencia de los ríos Aguacaliente y Grande de Orosi, a lo largo del posible trazo de falla Cachí. Estas terrazas se estima tienen edades iguales o menores a 12.000 años (GEOMATRIX CONSULTANTS, 1994).

La falla Urasca es una falla de $6 \mathrm{~km}$ de longitud y movimiento predominante normal con un rumbo oscilante cercano al norte-sur, que limita el sector este del lago de Cachí (Fig. 8, Cuadro 1). Al sur, la falla cambia a un rumbo entre SW y WSW, donde se continúa con la falla Cachí. La falla Urasca se identifica por su facetamiento triangular que mira al oeste (Fig. 9), el cual es más claro en su sector sur, perdiendo expresión hacia el norte, debido a la fuerte erosión ocurrida sobre la margen derecha del río Reventazón. Esta falla levanta el bloque este, donde afloran rocas volcánicas del Terciario Superior (Denyer \& Alvarado, 2007).

La depresión Ujarrás se encuentra limitada por las fallas Cachí, Urasca, Paraíso y Maravilla (ver adelante). Esta estructura transtensiva fue originalmente sugerida por GEOMATRIX CONSULTANTS (1994). Corresponde con una zona de cuenca que actualmente es ocupada por el embalse Cachí y el valle Ujarrás, donde han sido cartografiados depósitos lacustres y aluviales con edades menores a 12.000 años (Figs. 8 y 9; Dóndoli \& Torres, 1954; GEOMATRIX CONSULTANTS, 1994). Esta zona deprimida fue rellenada también con depósitos volcánicos relacionados con la actividad del macizo volcánico del Irazú, sobresaliendo la colada de lava de Cervantes Oriental (edad de 17.000 años; Alvarado \& Vega, 2013), asociada con el volcán monogenético Pasquí, que rellenó el borde noreste del valle Ujarrás.

La depresión Ujarrás parece corresponder con el caso de un único centro de subsidencia, controlado principalmente por el hundimiento asociado con la falla Urasca y en menor medida con la falla Paraíso. El relevo izquierdo entre las fallas Navarro-Cachí y Maravilla tiene una separación de $8 \mathrm{~km}$, mientras que el traslape entre ambas es de $4 \mathrm{~km}$.

\section{Segmento de falla Maravilla}

El sector oeste de esta falla, según nuestra interpretación, es similar con el trazo mostrado por Woodward \& Clyde (1993) con el nombre de falla Maravilla. Estos autores indican que la falla tiene expresión moderada y origina quiebres de pendiente, divisorias deformadas, cambios tonales en vegetación y su desplazamiento fue observado en el campo. Montero (2001) y Linkimer (2003) muestran una falla con un trazo similar llamándola falla Navarro. En este estudio preferimos usar el nombre de falla Maravilla, porque corresponde con el nombre original de la falla y porque se considera conveniente dividir el Sistema de Falla Navarro en segmentos de acuerdo con sus diferentes rumbos y cambios cinemáticos. La falla se extiende con un rumbo cercano al $\mathrm{N} 45-50^{\circ} \mathrm{E}$, desde el oeste de la población de Juan Viñas hasta el norte de la localidad de Colonia Guayabo, sobre la falda este del volcán Turrialba (Figs. 8 y 10). Su longitud se estima en $23 \mathrm{~km}$ (Cuadro 1).

La zona de conexión con la falla Paraíso se expresa mediante una zona de transtensión, definida por cuatro trazas de falla, con rumbos entre este-oeste y ENE. La traza del lado norte es bastante similar con el trazo propuesto por Linkimer (2003) para la falla Durán. De acuerdo con nuestra interpretación estas cuatro fallas originan desvíos izquierdos en el río Birris y en las quebradas Pacayas y Honda (Fig. 7B; sitios 5, 6, 7 y 8 en Fig. 8) y en el río Maravilla (sitios 1, 2 y 3 en Fig. 10). Continuando al este, la traza norte provoca un desvío izquierdo del río Chiz de $\sim 0,4$ km (sitio 4 en Fig. 10). Aguas abajo de la anterior traza de falla, el río drena sinuosamente un valle ancho por espacio de unos $500 \mathrm{~m}$ (Fig. 11). El río se localiza del lado oeste del valle, mientras que del lado este, un valle de unos $200 \mathrm{~m}$ de ancho se encuentra abandonado. Dentro de este valle, en varios afloramientos se reconocieron depósitos de pantano, cargados de materia orgánica (especialmente fragmentos de madera). Este paleo-pantano consideramos se relaciona con el alargamiento del perfil del río debido al desvío izquierdo del río Chiz asociado con la traza norte de la falla Maravilla y con el cambio de perfil 


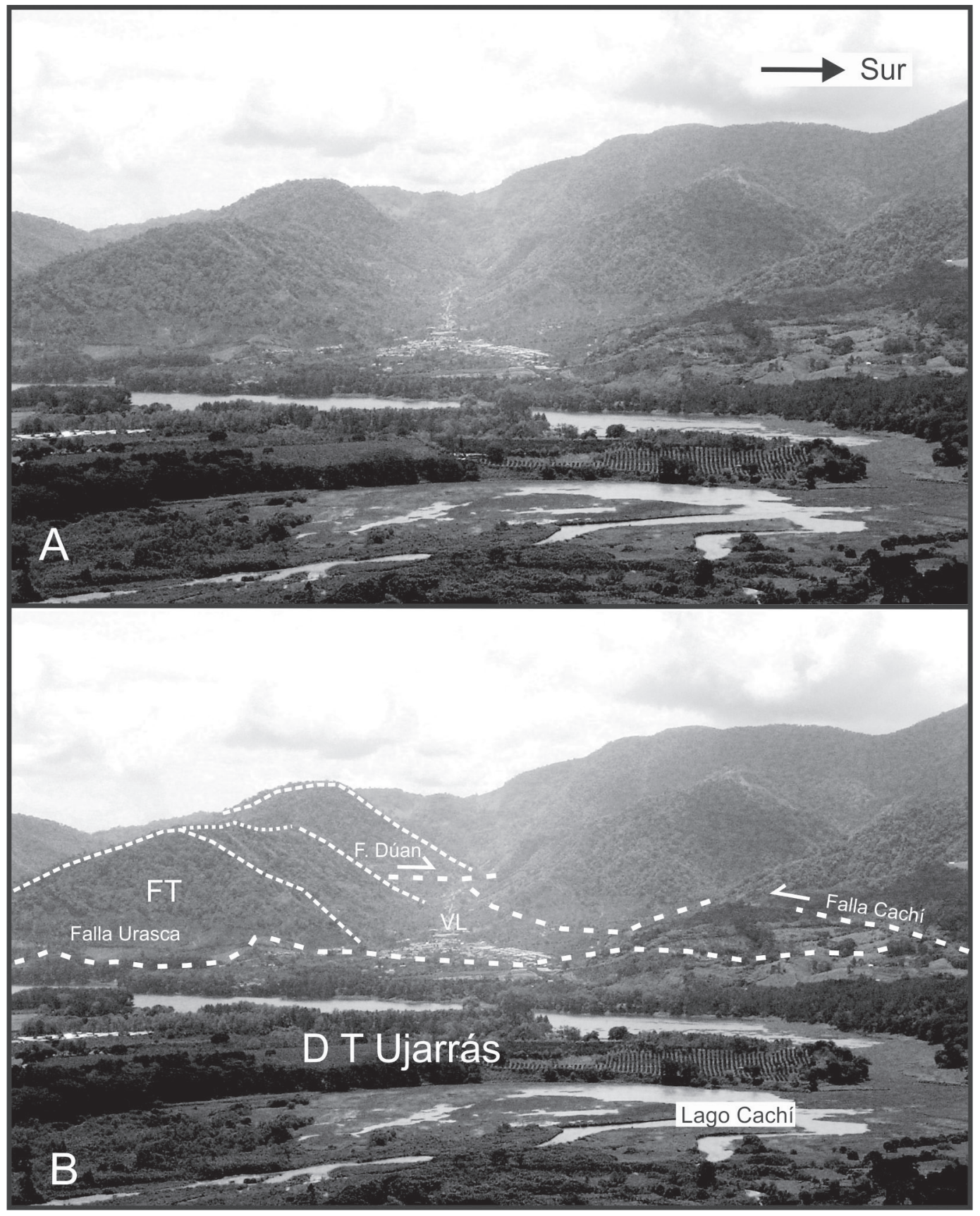

Fig. 9: Vista de la depresión tectónica Ujarrás, en el cual se localiza el lago Cachí y al lado izquierdo del mismo se ubican terrazas aluviales. A. Foto sin interpretar. B. Foto interpretada mostrando las fallas Cachí, Urasca y Dúan. La falla Cachí es desplazada a la derecha por la falla Dúan. La falla Urasca se reconoce por el escarpe de falla con facetas triangulares (FT). VL es el valle lineal del río Naranjo. Las trazas de falla se muestran como líneas discontinuas gruesas. Los bordes de las facetas triangulares se muestran como líneas discontinuas delgadas. La divisoria de la fila facetada se muestra con puntos blancos. 

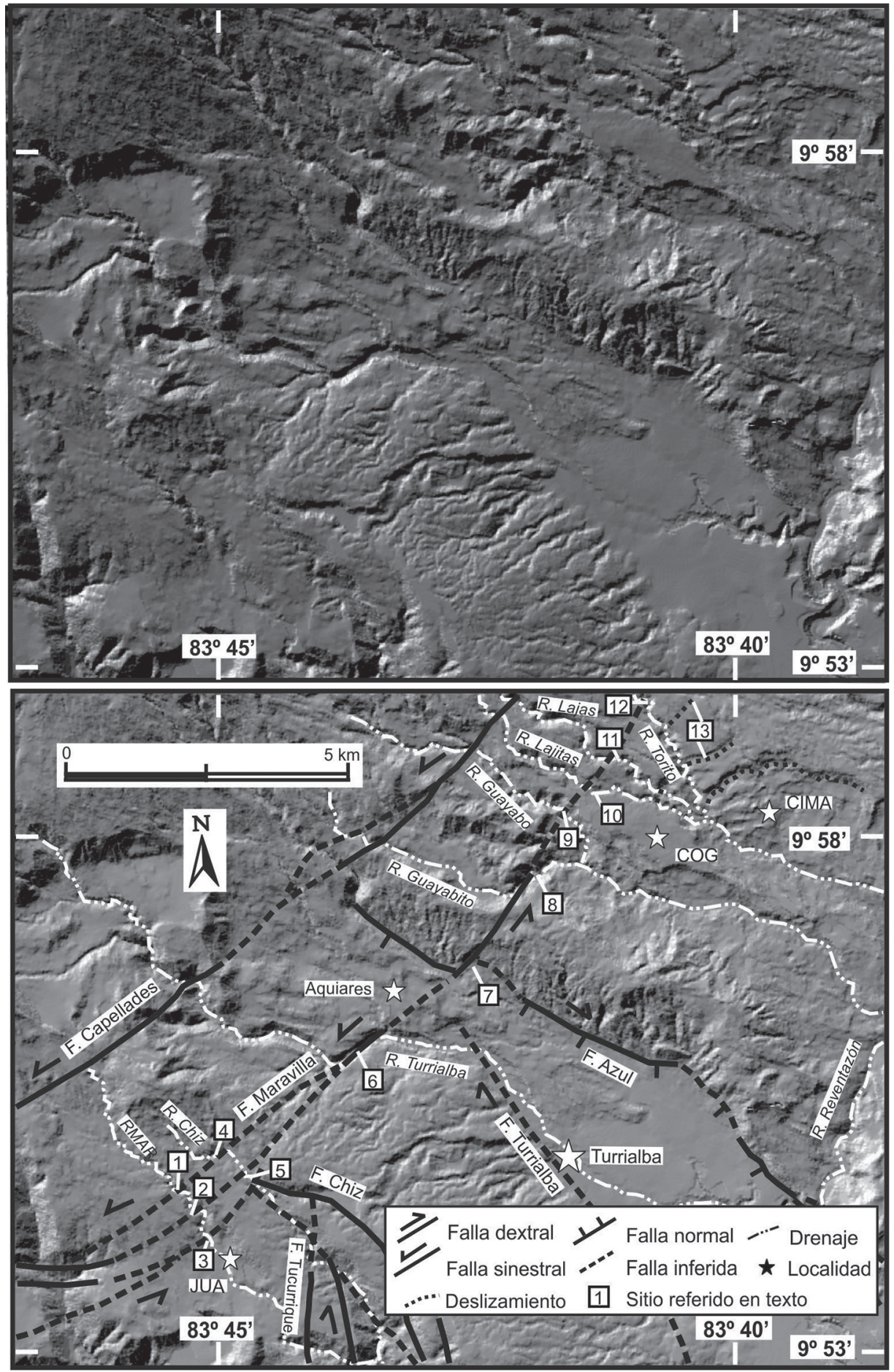

Fig. 10: Sector noreste del sistema de falla Navarro. A. Modelo de elevación digital del terreno (MED) sin interpretar. B. Interpretación de las fallas superpuestas sobre el MED. JUA, COG y CIMA son respectivamente las localidades de Juan Viñas, Colonia Guayabo y Cimarrones. RMAR es el río Maravilla. 


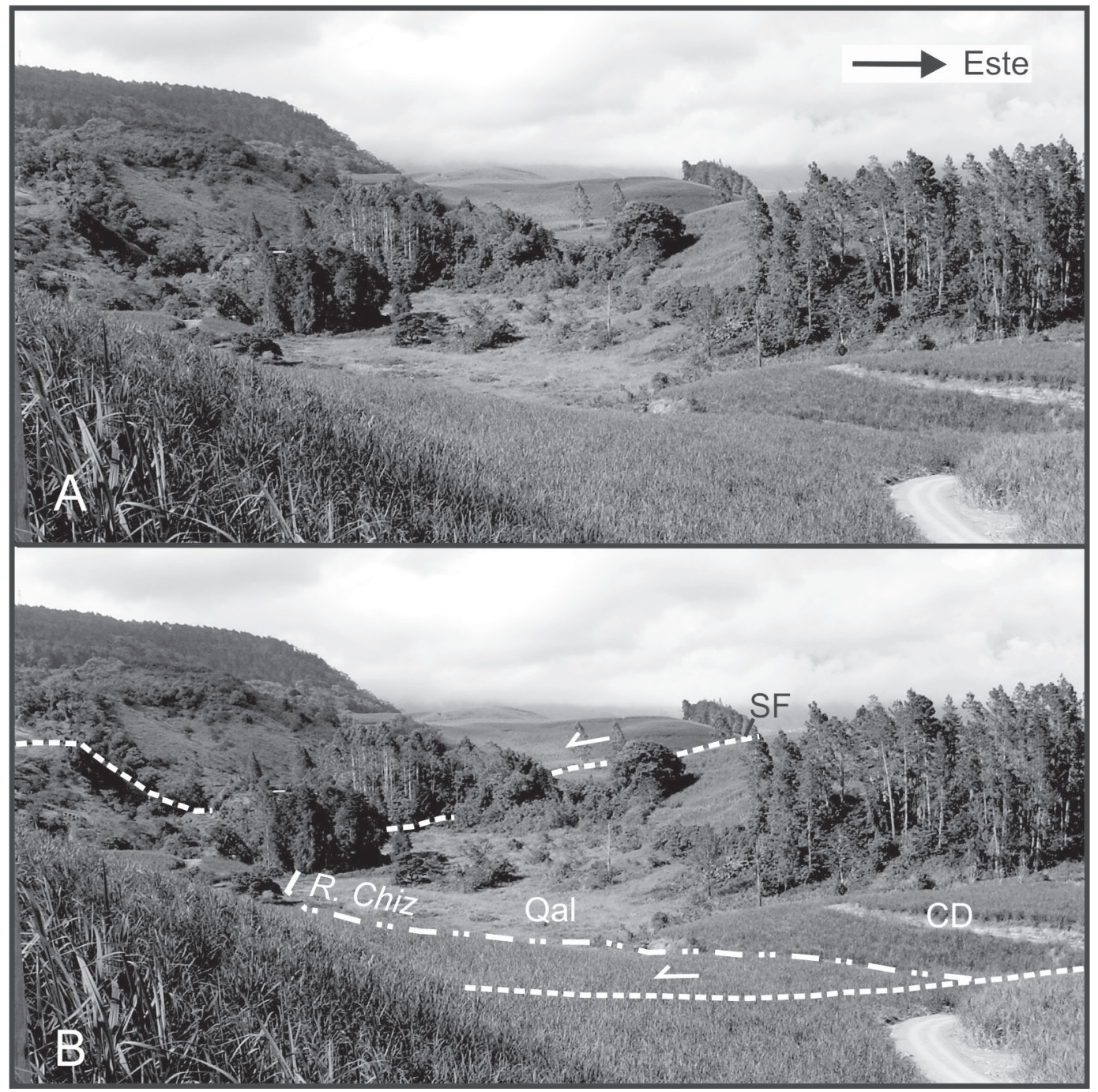

Fig. 11: Vista del depósito Cuaternario represado aguas abajo y aguas arriba del sector donde las diferentes trazas de la falla Maravilla (línea discontinua) cruzan el río Chiz (línea de doble punto). A. Foto sin interpretar. B. Foto interpretada muestra la traza norte de la falla Maravilla al fondo de la foto, que sale a un valle ancho luego de tener un desvío izquierdo de unos 0,4 km (ver Fig. 10). Esa traza pasa por una silla de falla (SF). En primer plano la traza sur origina el desvío de una colina (CD).

del río al salir de una zona de mayor pendiente. Asimismo, las dos trazas del sur, al cruzar el cauce del río Chiz originan el desplazamiento de una colina de rumbo ENE de $10 \mathrm{~m}$ de altura hacia el centro del valle fluvial (sitio 5 en Fig. 10; CD en Fig. 11B). Del lado este de la colina existe un pequeño valle abandonado, desplazado a la izquierda unos $30 \mathrm{~m}$ con respecto del curso actual, el cual parece corresponder con el curso fluvial anterior que poseía el río Chiz y que fue desplazado por la falla Maravilla. Actualmente, el río Chiz le da vuelta a la colina por el lado oeste al atravesar la zona de falla (Fig. 11).

La falla continúa con una sola traza donde ocurre el desvío del río Turrialba, el cual se estima es $\sim 1 \mathrm{~km}$ (sitio 6 en Fig. 10; Linkimer, 2003). En los alrededores de la localidad de Aquiares, la traza pierde prominencia a lo largo de $2 \mathrm{~km}$, al cruzar los depósitos del debris avalanche de Angostura asociado con el deslizamiento de Coliblanco, de 
unos 17.000 años (Alvarado et al., 2004). Al cruzar el escarpe de la falla Azul, la falla Maravilla vuelve a tener una expresión prominente. El escarpe de la falla Azul es desplazado a la izquierda por la falla Maravilla. Sin embargo, la magnitud del desvío es imprecisa por la posible existencia de un deslizamiento en este sector. Montero et al. (2013a) sugieren un desplazamiento del orden de metros, aunque el desvío puede alcanzar un valor máximo de hasta $650 \mathrm{~m}$ (sitio 7 en Fig. 10).

Continuando al NE, se han identificado cinco desvíos sinestrales, en los cauces de los ríos Guayabito $(\sim 1 \mathrm{~km}$, sitio 8 en Fig. 10; Linkimer, 2003), Guayabo, Lajitas, Lajas y Torito (sitios 9, 10, 11 y 12 respectivamente en Fig. 10). Más al NE, la falla Maravilla pierde prominencia fuera del área de estudio (Fig. 1).

El gran deslizamiento de Cimarrones cuya corona tiene $2,5 \mathrm{~km}$ de diámetro se localiza unos $2 \mathrm{~km}$ al SE de la traza de la falla. Es el segundo deslizamiento de mayor volumen sobre la margen occidental del río Reventazón (Segura et al., 2011). Al NW de la corona de este deslizamiento, existen una serie de grietas sub-paralelas a la falla $\mathrm{y}$ al deslizamiento que se localizan a unos $1,5 \mathrm{~km}$ y $0,5 \mathrm{~km}$ de la traza de falla (indicadas con el número 13 en Fig. 10), cuyo origen no es claro si se relacionan con una propagación del deslizamiento hacia el NW o con trazas de falla secundarias asociadas con la falla Maravilla. No se descarta la posibilidad de que este deslizamiento haya sido disparado por un terremoto histórico ocurrido en esta falla, o en otras cercanas.

\section{SISMICIDAD}

Durante la época Colonial y el siglo XIX, los estudios sobre sismicidad histórica no evidencian terremotos asociados con el Sistema de Falla Navarro (i.e., Peraldo \& Montero, 1994; Peraldo \& Montero, 1999).

A partir del siglo XX, en cambio, si existen evidencias de sismos con un posible origen en este sistema de fallas. Por ejemplo, en el mes de agosto, luego del terremoto de Cartago de mayo de 1910 (Ms 6,3), varios temblores fueron sentidos con intensidad entre débil y fuerte en localidades ubicadas en el sector oeste del sistema Navarro como San Cristóbal, Frailes y Rosario (Peraldo \& Montero, 2010). En forma similar, un sismo ocurrido el 22 de marzo de 1933 fue sentido con una intensidad alta (de 5,5 en la escala RossiForel) en localidades ubicadas en el sector este del sistema Navarro como Pacayas y Santa Cruz (Schaufelber, 1933; Ambraseys \& Adams, 2001). Tanto los sismos de 1910, como el de 1933, pudieron haberse originado en alguna de las trazas de la falla Navarro que se ubican en las zonas donde se alcanzaron las intensidades más altas, no obstante, su origen sigue siendo incierto ya que se carece de una localización precisa de los hipocentros y además en las zonas de altas intensidades coexisten otros sistemas de fallas adicionales al sistema Navarro que pudieron provocar estos sismos.

El terremoto histórico más significativo que pudo haberse originado en el Sistema de Falla Navarro es el terremoto de Paraíso del 22 de agosto de 1951 (5,4 Ms, Boschini, 1989; Montero \& González, 1990; Ambraseys \& Adams, 2001; GEOMATRIX CONSULTANTS, 1994; Montero, 2001). Este sismo causó intensidades de VII (Mercalli Modificada, MM) en las localidades de Paraíso, Navarro, Orosi, Palomo y Cachí (Fig. 12, Cuadro 2). La primera localidad se ubica sobre terreno firme mientras que las restantes se localizan sobre terrenos aluviales. En Paraíso 62 casas sufrieron daños y 30 quedaron inhabitables, además de daños en la iglesia y escuela y la ruptura de la cañería. Los daños se concentraron especialmente en casas de bahareque construidas en el Barrio La Joya ubicado en el este de la ciudad. En Orosi hubo daños en casas y en la iglesia en la cual se produjeron agrietamientos y gran caída de repello (Fig. 12A). El sismo fue sentido en forma leve en localidades como Limón y Puntarenas y no fue sentido en la provincia de Guanacaste (Fig 12B). La distribución de las intensidades más altas sugiere que el epicentro macrosísmico de este terremoto se puede ubicar ya sea en la zona de conexión entre las fallas Navarro y Paraíso (Fig. 12C) o en la falla Orosi.

A partir de la década de 1970 cuando se dio el incremento en la instrumentación sismológica liderado por la Escuela Centroamericana de Geología y la Red Sismológica Nacional (RSN) 

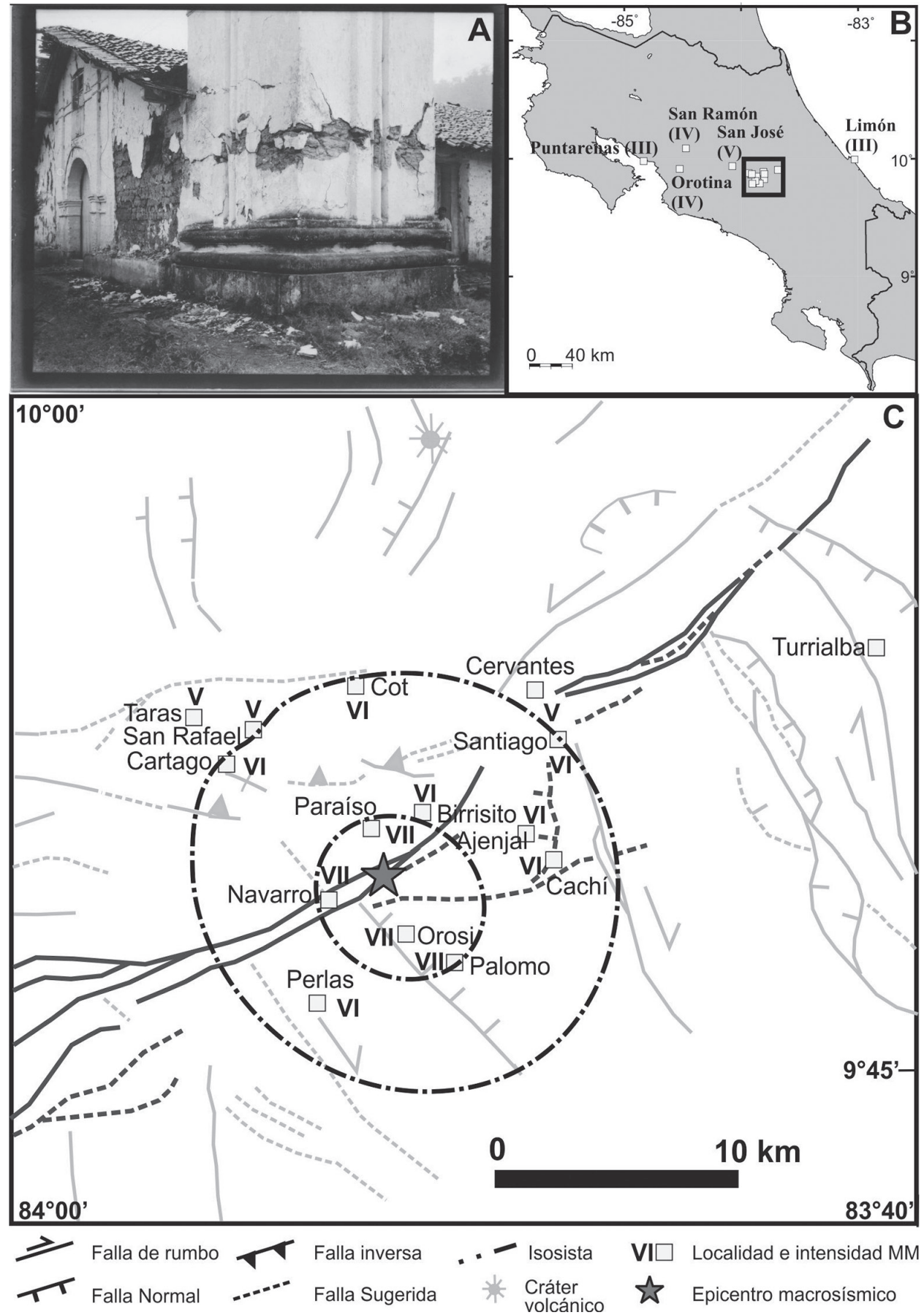

Fig. 12. A. Daños en la iglesia de Orosi ocasionados por el terremoto del 22 de agosto de 1951 (Fotografía de Rodolfo Carrillo). B. Mapa de localidades distantes con datos de intensidad del terremoto de 1951. El recuadro muestra la zona mostrada en la parte C. C. Mapa de isosistas de la zona mesosísmica del terremoto de 1951. El valor de intensidad Mercalli Modificada (MM) estimado se muestra para cada localidad (Cuadro 2). Las trazas relacionadas con el sistema de falla Navarro se muestran en gris oscuro y el resto de fallas de la zona en gris claro. 
Cuadro 2

Intensidades (MM) del terremoto de Paraíso.

\begin{tabular}{ccc}
\hline Localidad & $\begin{array}{c}\text { Intensidad } \\
(\mathrm{MM})\end{array}$ & $\begin{array}{c}\text { Distancia al epicentro } \\
(\mathrm{km})\end{array}$ \\
\hline Navarro & VII & 3 \\
Paraíso & VII & 3 \\
Orosi & VII & 3 \\
Birrisito & VI & 4 \\
Palomo & VII & 5 \\
Ajenjal & VI & 6 \\
Cachí & VI & 6 \\
Perlas & VI & 6 \\
Cot & VI & 7 \\
Cartago & VI & 7 \\
San Rafael de & V? & 7 \\
Oreamuno & & \\
Santiago & V & 8 \\
Cervantes & V & 9 \\
Taras & V & 10 \\
San José & V & 26 \\
Heredia & III? & 34 \\
Alajuela & III? & 44 \\
San Ramón & IV? & 72 \\
Orotina & IV? & 73 \\
Limón & III? & --- \\
Puntarenas & III? & \\
Guanacaste & II & 57 \\
\hline & & 5 \\
\hline
\end{tabular}

se ha podido asociar con más certeza el origen de varios sismos con el Sistema de Falla Navarro (Fig. 13). Estos incluyen los enjambres de diciembre de 1977 y setiembre de 1980 (Aguilar, 1984). Estos enjambres se caracterizaron por magnitudes menores a 4,1 y profundidades de entre 5 y $10 \mathrm{~km}$. La dispersión epicentral no permite definir cual o cuales fallas del sistema Navarro originaron estos enjambres, no obstante, la mayor concentración de eventos se localizó al este de la zona transtensiva Estrella en la zona donde la falla Tarrazú Norte alcanza a la falla Navarro (Fig. 13B).

El segundo sismo en importancia que puede relacionarse con el sistema Navarro fue el ocurrido el 9 de agosto de 1991 (Mw 5,2, Fig. 13B). Este sismo causó daños de moderados a severos en alrededor de 100 casas en la zona de Corralillo, San Antonio, Santa Elena, Frailes y Llano Los Ángeles (Barquero et al., 1991). La localización epicentral de este evento mostrada por Montero (1994), sugiere que el mismo se localizó sobre el sector oeste de la falla Navarro, al pie del escarpe de falla que se ubica del lado norte del río San Cristóbal Norte (Figs. 2, 4, 5A y 13B, Cuadros 1 y 3). La solución del mecanismo focal obtenida por Dziewonski et al. (1992) es transcurrente pura con movimiento sinestral en el plano nodal de rumbo NE (mecanismo focal número 1 en Cuadro 3 y Fig. 13B) lo cual es consistente con el movimiento y rumbo de la falla en ese sector.

En el mes de agosto de 1991 otros dos eventos de magnitud 3,0 y 2,6 (Quintero y Güendel (2000) presentaron una localización epicentral que sugiere un origen en la falla Tarrazú Norte.

En el sector norte de la ciudad de Turrialba, 17 sismos aislados espacial y temporalmente (y no en enjambres como los de 1977 y 1980) fueron localizados en el período de 1992 a 2002, en la zona cercana al extremo noreste de la falla Maravilla y también en la zona cercana a la intersección entre esta falla y las fallas Azul y Turrialba y otros segmentos del Sistema de Falla Atirro (Linkimer, 2003). Estos sismos se caracterizaron por magnitudes bajas (ML 2,0-3,7) y profundidades menores a $15 \mathrm{~km}$ y podrían tener su origen en las fallas del sistema Navarro o en alguna de las otras fallas cercanas relacionadas con el sistema Atirro.

Con el fin de analizar la sismicidad superficial $(<30 \mathrm{~km})$ reciente en la zona del Sistema de Falla Navarro, para este estudio se realizó una búsqueda de los sismos con la mejor calidad de localización en el catálogo de la RSN para el periodo 1973-2015 (Fig. 13A). Los criterios usados para la selección de los sismos fueron: tener lecturas de al menos 15 estaciones, un valor de la raíz cuadrática media (RMS) menor a 1,0 y un gap de cobertura azimutal menor a 180 grados. Esta búsqueda resultó en 428 sismos ubicados en la parte central del país (Fig. 13A). La distribución de los epicentros muestra que las concentraciones de sismos más significativas han ocurrido en Cartago, al sureste de San José y suroeste del volcán Irazú. El Sistema de Falla Navarro en particular solamente se ilumina en su sector suroeste especialmente en 


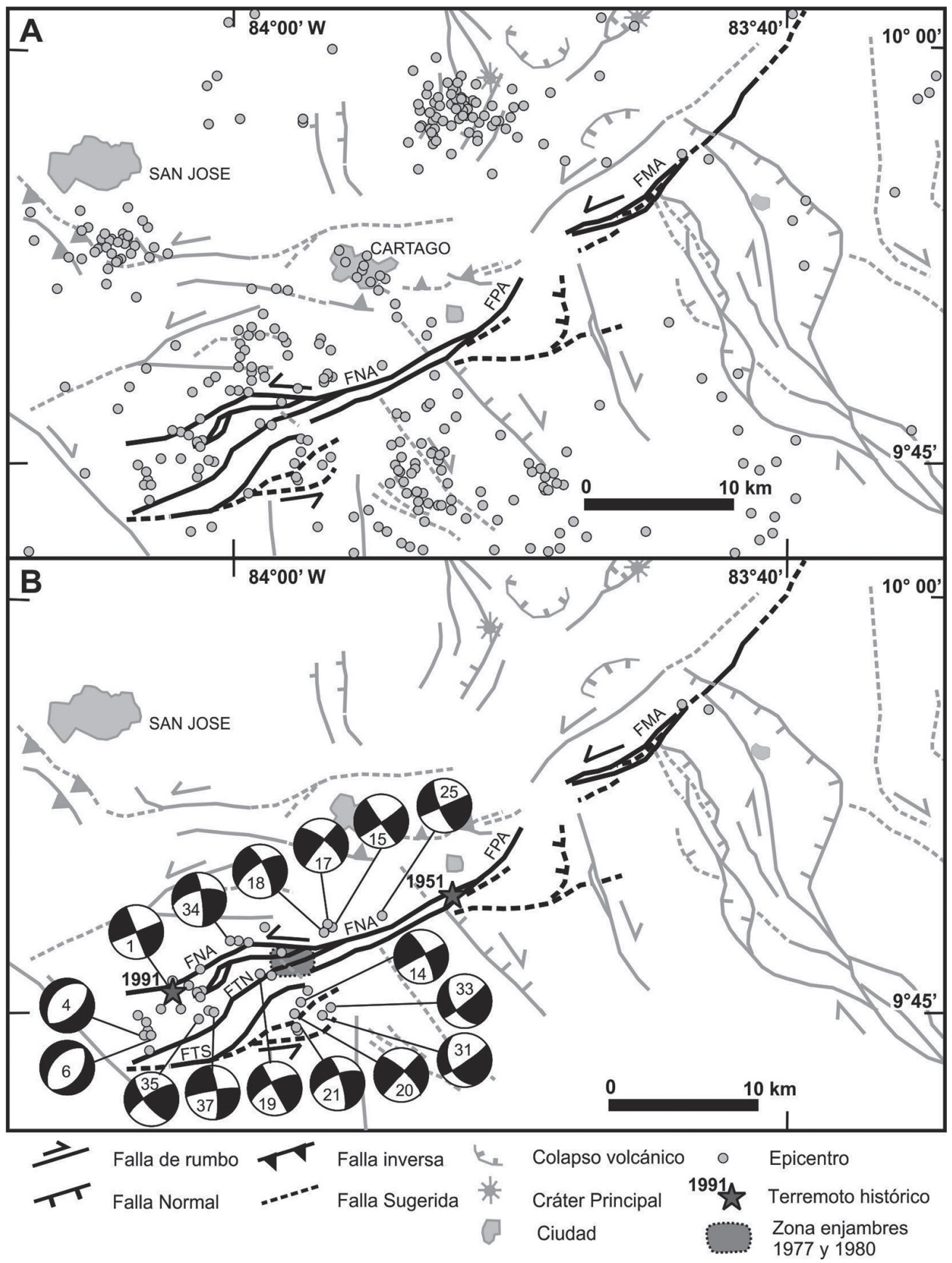

Fig. 13: A. Sismicidad en la zona central-este de Costa Rica localizada usando al menos 15 estaciones de la RSN en periodo 1973-2015. B. Sismicidad relacionada con el sistema de fallas Navarro. Los círculos grises muestran la sismicidad relocalizada en la vecindad de las trazas del sistema de falla Navarro con indicación de la solución de los mecanismos focales para los casos en que fue posible calcularlos (Cuadro 3 y Fig. 14). Las estrellas denotan los epicentros de los sismos de Paraíso de 1951 (Ms 5,4) y Frailes de 1991 (Mw 5,2). La zona de los enjambres de 1977 y 1980 corresponde con la descrita por Aguilar (1984). Las trazas relacionadas con el sistema de falla Navarro se muestran en gris oscuro y el resto de fallas de la zona en gris claro. FTN, FTS, FNA, FPA y FMA denotan respectivamente las fallas Tarrazú Norte, Tarrazú Sur, Navarro, Paraíso y Maravilla. 
la zona de tracción Estrella, en donde el catálogo sísmico posee 37 eventos ubicados cerca $(<3 \mathrm{~km})$ de la traza de las fallas Navarro, Tarrazú Norte y Tarrazú Sur (Fig. 13B). El sector noreste del sistema Navarro, en cambio, carece de sismicidad y solamente dos sismos se localizan cerca de la falla Maravilla (Fig. 13B).

Los sismos ubicados a menos de $3 \mathrm{~km}$ de las trazas del Sistema de Falla Navarro (39 en total) fueron revisados, relocalizados y se les efectuó el cálculo del mecanismo focal (Figs. 13B y 14). La localización de estos sismos se realizó con entre 15 y 39 estaciones y cumpliendo con el criterio de un gap de cobertura azimutal menor a 180 grados y en la mayoría de los casos con una estación a menos de $5 \mathrm{~km}$ del epicentro. Los sismos fueron procesados y analizados con el programa SEISAN (Öttemoller et al., 2011) y localizados usando el modelo de velocidad que la RSN usa rutinariamente, el cual está basado en Matumoto et al. (1977).

De los 39 sismos, 15 poseen un mecanismo focal de buena calidad (Figs. 13B y 14). Cada mecanismo focal fue calculado usando el programa FOCMEC (Snoke, 1984) a través de observaciones de la polaridad del primer arribo de la onda P. Los mecanismos fueron calculados con entre 10 y 40 observaciones de polaridades. La búsqueda de los planos nodales que separan las regiones con distinta polaridad se efectuó cada cinco grados y todas las soluciones con cero errores en la separación de las polaridades son mostradas en la Fig. 14.

La mayoría de los mecanismos focales obtenidos corresponden con fallas de desplazamiento de rumbo (Figs. 13B y 14; Cuadro 3). Únicamente dos mecanismos focales corresponde con fallas normales (números 4 y 6, en Fig. 13B) y estos se ubican al suroeste de la zona de tracción Estrella, en donde esfuerzos de tensión pueden ser explicados por el traslape izquierdo entre las fallas Navarro y Tarrazú Sur.

El resto de mecanismos focales (13) poseen un plano nodal de rumbo NE-SW o cercano al este-oeste de tipo sinestral puro (Cuadro 3), lo cual es consistente con el rumbo y tipo de movimiento deducido a través de las observaciones morfotectónicas. Cinco mecanismos focales pueden ser asociados con la falla Navarro (números 15, 17, 18, 25 y 34 Fig. 13B), tres con la falla Tarrazú
Norte (números 19, 35 y 37, Fig. 13B) y cinco con trazas relacionadas con la falla Tarrazú Sur (14, 20, 21, 31 y 33, Fig. 13B).

\section{CONCLUSIONES}

El Sistema de Falla Navarro es uno de principales localizados dentro del CDCCR, con una longitud total de los segmentos que alcanza aproximadamente $115 \mathrm{~km}$ (Fig. 2 y Cuadro 1). El Sistema de Falla Navarro se caracteriza por un rumbo entre este-oeste y $\mathrm{N} 40^{\circ} \mathrm{E}$ y un movimiento principalmente sinestral y en algunos segmentos con una componente normal. El sistema incluye cinco segmentos de falla denominados: Tarrazú, Navarro, Cachí, Paraíso y Maravilla y dos estructuras transtensivas denominadas Estrella y Ujarrás, las cuales responden a relevos izquierdos entre las fallas Tarrazú y Navarro y NavarroCachí y Maravilla, respectivamente.

La geometría, expresión geomorfológica y sismicidad observadas dentro de la zona transtensiva Estrella sugieren que las fallas Navarro, Tarrazú Sur y Norte se encuentran activas. La geomorfología y los depósitos aluviales sugieren que la zona de tracción Estrella se encuentra en un estado incipiente en su desarrollo. Por otro lago, la geometría, expresión geomorfológica y sismicidad sugieren que las fallas Cachí y Urasca son inactivas y las fallas Paraíso y Maravilla son activas sin sismicidad asociada.

El terremoto de Paraíso del 22 de agosto de 1951 (5,4 Ms) es el terremoto histórico más significativo que pudo haberse originado en el Sistema de Falla Navarro. La distribución de las intensidades más altas sugiere que el epicentro macrosísmico de este terremoto se puede ubicar ya sea en la zona de conexión entre las fallas Navarro y Paraíso o en la falla Orosi El segundo sismo en importancia que puede relacionarse con el sistema Navarro fue el ocurrido el 9 de agosto de 1991 (Mw 5,2), conocido como sismo de Frailes. La localización epicentral y mecanismo focal son consistentes con un origen en la falla Navarro.

Durante el periodo 1973-2015, se ha determinado la ocurrencia de sismos aislados y en pequeños enjambres en diferentes segmentos 
Cuadro 3

Soluciones de mecanismos focales

\begin{tabular}{|c|c|c|c|c|c|c|c|c|c|c|c|}
\hline \multirow{3}{*}{ \# } & \multirow{3}{*}{ Fecha } & \multirow{3}{*}{ Mw } & \multirow{3}{*}{ R. } & \multirow{3}{*}{ I. } & \multirow{3}{*}{ Ra. } & \multirow{3}{*}{$\begin{array}{l}\text { Tipo de falla de } \\
\text { cada plano nodal }\end{array}$} & \multicolumn{4}{|c|}{ Ejes } & \multirow{3}{*}{ Po } \\
\hline & & & & & & & \multicolumn{2}{|c|}{ Comp. } & \multicolumn{2}{|c|}{ Tensión } & \\
\hline & & & & & & & R. & I. & R. & I. & \\
\hline \multirow[t]{2}{*}{1} & 09-08-91 (*) & 5,2 & 68 & 90 & 0 & Sinestral & 23 & 0 & 113 & 0 & -- \\
\hline & & & 158 & 90 & -180 & Dextral & & & & & \\
\hline \multirow[t]{2}{*}{4} & $16-04-05$ & 3,4 & 48 & 55 & -84 & Normal & 161 & 79 & 134 & 10 & 19 \\
\hline & & & 38 & 35 & -99 & Normal & & & & & \\
\hline \multirow[t]{2}{*}{6} & $16-04-05$ & 2,9 & 45 & 45 & -83 & Normal & 42 & 85 & 130 & 0 & 13 \\
\hline & & & 35 & 45 & -97 & Normal & & & & & \\
\hline \multirow[t]{2}{*}{14} & $16-06-12$ & 3,6 & 62 & 89 & -15 & Sinestral & 16 & 11 & 108 & 10 & 10 \\
\hline & & & 152 & 75 & -179 & Dextral & & & & & \\
\hline \multirow[t]{2}{*}{15} & $15-09-12$ & 3,7 & 55 & 86 & -3 & Sinestral & 10 & 5 & 100 & 1 & 15 \\
\hline & & & 145 & 87 & -176 & Dextral & & & & & \\
\hline \multirow[t]{2}{*}{17} & $15-09-12$ & 3,2 & 38 & 87 & -20 & Sinestral & 172 & 16 & 85 & 11 & 12 \\
\hline & & & 129 & 70 & -176 & Dextral & & & & & \\
\hline \multirow[t]{2}{*}{18} & $15-09-12$ & 3,6 & 56 & 67 & -20 & Sinestral & 16 & 30 & 104 & 3 & 12 \\
\hline & & & 154 & 71 & -156 & Normal-Dextral & & & & & \\
\hline \multirow[t]{2}{*}{19} & $12-11-12$ & 3,6 & 60 & 70 & 0 & Sinestral & 17 & 14 & 104 & 14 & 14 \\
\hline & & & 151 & 90 & 160 & Dextral & & & & & \\
\hline \multirow[t]{2}{*}{20} & $18-01-13$ & 3,6 & 43 & 89 & -15 & Sinestral & 177 & 11 & 89 & 10 & 15 \\
\hline & & & 133 & 75 & -179 & Dextral & & & & & \\
\hline \multirow[t]{2}{*}{21} & $07-08-13$ & 3,3 & 66 & 64 & -16 & Sinestral & 27 & 29 & 113 & 7 & 15 \\
\hline & & & 163 & 76 & -153 & Normal-Dextral & & & & & \\
\hline \multirow[t]{2}{*}{25} & $06-03-14$ & 3,7 & 66 & 90 & 15 & Sinestral & 20 & 11 & 112 & 11 & 17 \\
\hline & & & 156 & 75 & -180 & Dextral & & & & & \\
\hline \multirow[t]{2}{*}{31} & $18-12-14$ & 2,5 & 55 & 82 & -50 & Normal-Sinestral & 2 & 39 & 115 & 26 & 11 \\
\hline & & & 154 & 41 & -168 & Dextral & & & & & \\
\hline \multirow[t]{2}{*}{33} & $07-04-15$ & 2,4 & 51 & 83 & -37 & Normal-Sinestral & 2 & 31 & 105 & 20 & 18 \\
\hline & & & 147 & 53 & -171 & Dextral & & & & & \\
\hline \multirow[t]{2}{*}{34} & $10-04-15$ & 2,8 & 77 & 62 & -11 & Sinestral & 38 & 27 & 122 & 12 & 22 \\
\hline & & & 172 & 80 & -152 & Normal-Dextral & & & & & \\
\hline \multirow[t]{2}{*}{35} & $15-05-15$ & 2,6 & 57 & 75 & 20 & Inversa-Sinestral & 9 & 3 & 100 & 25 & 19 \\
\hline & & & 142 & 71 & 164 & Dextral & & & & & \\
\hline 37 & $22-06-15$ & 3,4 & 81 & 84 & -14 & Sinestral & 36 & 14 & 127 & 5 & 40 \\
\hline & & & 173 & 76 & -174 & Dextral & & & & & \\
\hline
\end{tabular}

(*) Solución de Dziewonski et al. (1992)

R.: Rumbo, I.: Inclinación del plano nodal, Ra.: ángulo de Rake, Pol.: Número de polaridades. 

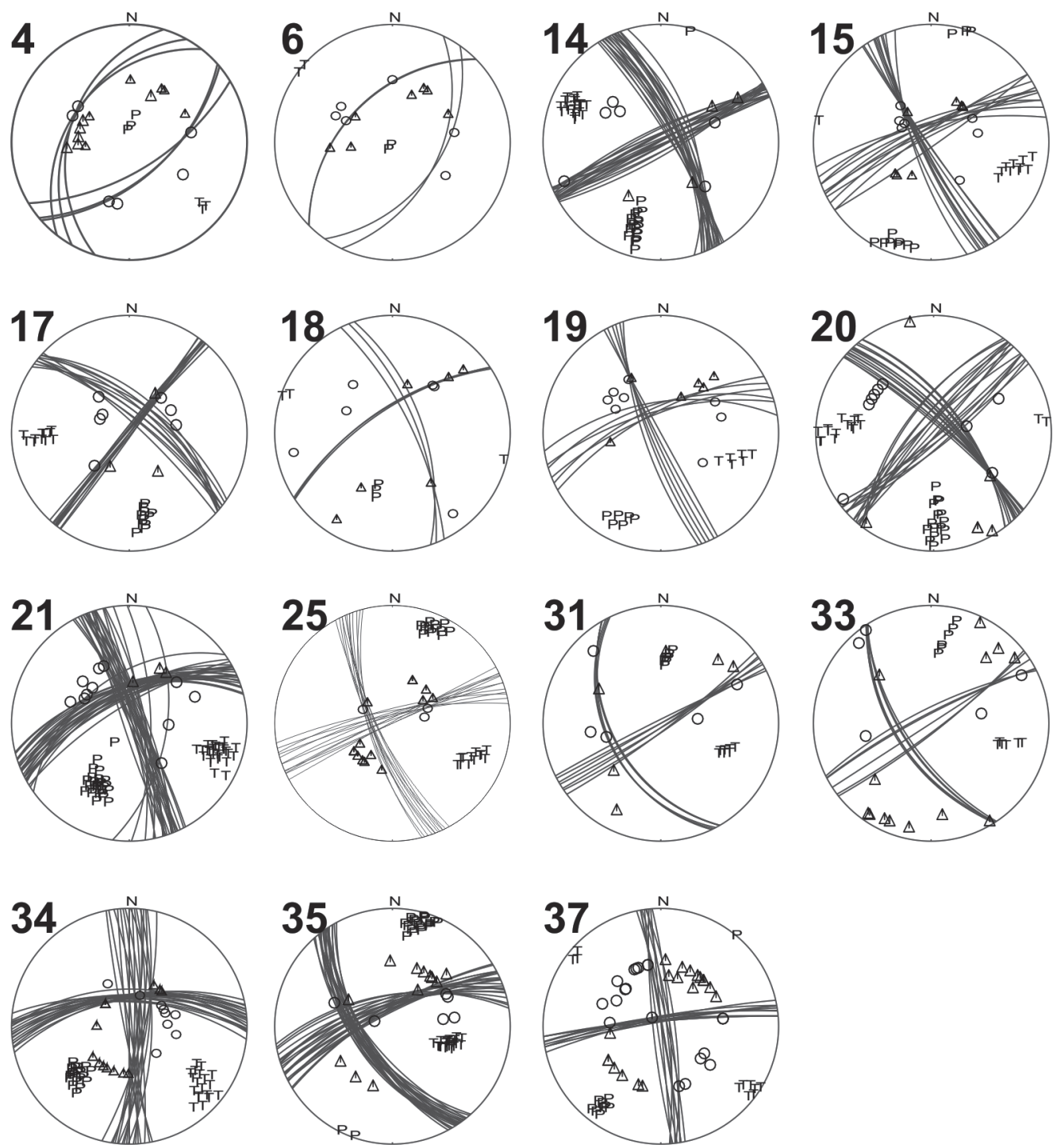

Fig. 14: Mecanismos focales de los sismos ubicados en la vecindad de las trazas del sistema de falla Navarro. Los números en cada mecanismo focal corresponden con los mostrados en el Cuadro 3 y Fig. 13B. Las soluciones de los planos nodales se muestran cada cinco grados logrando una separación de polaridades con cero errores. P y T representan los ejes de Compresión y Tensión, respectivamente. Los círculos y triángulos representan polaridades positivas y negativas, respectivamente.

de la falla particularmente dentro de la estructura transtensiva Estrella. La mayoría de mecanismos focales calculados corresponden con fallas de desplazamiento de rumbo con un plano nodal de rumbo NE-SW o cercano al este-oeste de tipo sinestral puro, lo cual es consistente con las observaciones morfotectónicas. Debido a su extensión y ubicación geográfica el Sistema de Falla Navarro constituye una amenaza sísmica significativa para la región central de Costa Rica. 


\section{AGRADECIMIENTOS}

Este estudio es parte de los proyectos 830-B1504 "Estudio de la tectónica activa del sistema de fallas de Aguacaliente y Navarro del Valle Central mediante Técnicas Geodésicas y Paleosísmicas: contribución para la mejora de la evaluación de la amenaza sísmica" y 113-B3-129 "Estudio de la tectónica activa de las fallas del Cinturón Deformado del Centro de Costa Rica", ambos financiados por la Universidad de Costa Rica y el primero además mediante el Fondo de Incentivos del Ministerio de Ciencia y Tecnología, proyecto CONICIT FI-01210. Se agradece a Elena Badilla por proporcionar los modelos de elevación digital del terreno que sirvieron de base para dibujar varias figuras de este trabajo. Agradecemos la colaboración de los asistentes de la Red Sismológica Nacional: Darío Cerdas, Juan Luis Porras, Carlos Chamorro y Kevin Godínez.

\section{REFERENCIAS BIBLIOGRÁFICAS}

AGUILAR, A., 1984: Sismicidad del 3 al 9 de setiembre de 1980 y su relación con la geología en la cabecera del río Navarro, Cartago.- 104 págs. Univ. de Costa Rica, San José [Tesis Lic.].

ALVARADO, G. E. \& GANS, P. B., 2012: Síntesis geocronológica del magmatismo, metamorfismo y metalogenia de Costa Rica, América Central.- Rev. Geol. Amér. Central, 46: 7-122.

ALVARADO, G. E. \& VEGA, A., 2013: La geomorfología de la colada de Cervantes, volcán Irazú (Costa Rica): descripción de uno de los campos de lava más grandes de América Central.- Rev. Geol. Amér. Central, 48: 99-118.

ALVARADO, G., VEGA, E., CHAVES, J. \& VÁSQUEZ, M., 2004: Los grandes deslizamientos (volcánicos y no volcánicos) de tipo debris avalanche en Costa Rica.- Rev. Geol. Amér. Central, 30: 83-99.
AMBRASEYS, N. \& ADAMS, A., 2001: The seismicity of Central America. A descriptive catalogue 1898-1995.- 104 págs. Imperial College Press, Londres.

ARIAS, O. \& DENYER, P., 1990: Geología de la hoja Caraigres.- Escala 1: 50 000, IGN, San José.

ARIAS, O. \& DENYER, P., 1991: Estructura geológica de la región comprendida en las hojas topográficas Abra, Caraigres, Candelaria y Río Grande, Costa Rica.Rev. Geol. Amér. Central, 12: 61-74.

BARQUERO, R., ROJAS, W., CLIMENT, A. \& MONTERO, W., 1991: El temblor del 9 de agosto de 1991 (Costa Rica). Informe Sismológico.- 14 págs. ICE-Dirección de Ingeniería Civil- Dep. de Geología, San José [Inf. interno].

BERRANGÉ, J. P., 1977: Reconaissance geology of the Tapantí Quadrangle, Talamanca Cordillera, Costa Rica (including notes on photogeological maps of the Pejibaye, Vueltas, Savagre and San Isidro Quadrangles).- 77 págs. Inst. Geol. Sci. Overseas Division, Londres.

BOSCHINI, I. M., 1989: Incidencia de las fuentes sísmicas en la región caribe de Costa Rica.- 97 págs. Univ. Costa Rica, San José [Tesis Lic.].

COLLINS, L. S., COATES, A. G., JACKSON, J. B. C. \& OBANDO, J., 1995: Timing and Rates of Emergence of the Limon and Bocas del Toro Basins: Caribbean Effects of Cocos Ridge Subduction.- En MANN. P. (ed.): Geologic and Tectonic Development of the Caribbean Plate Boundary in Southern Central America.Geol. Soc. Amer. Spec. Pap. 295: 263-290.

DE BOER, J., DRUMMOND, M., BORDELON, M., DEFANT, M., BELLON, H. \& MAURY, 
R., 1995: Cenozoic Magmatic Phases of the Costa Rican Island Arc (Cordillera de Talamanca).- En MANN. P. (ed.):Geologic and Tectonic Development of the Caribbean Plate Boundary in Southern Central America.Geol. Soc. Amer. Spec. Pap. 295: 35-55.

DENYER, P. \& ALVARADO, G. E., 2007: Mapa geológico de Costa Rica.- Escala 1:400 000, Librería Francesa, San José.

DENYER, P. \& ARIAS, O., 1991: Estratigrafía de la región central de Costa Rica.- Rev. Geol. Amér. Central, 12: 1-59.

DENYER, P. \& MONTERO, W., 1988: Mapa geoestructural y de sismos del Valle Central.- Escala 1: 150 000, IGN, San José.

DENYER, P., MONTERO, W. \& ALVARADO, G., 2003: Atlas tectónico de Costa Rica.81 págs. Ed. Universidad de Costa Rica, San José.

DÓNDOLI, C. \& CHAVES, R., 1968: Mapa adjunto al estudio geológico del Valle Central.- Escala 1: 150 000, IGN, San José.

DÓNDOLI, C. \& TORRES, A., 1954: Estudio geoagronómico de la región oriental de la Meseta Central.- 180 págs. Min. Agricultura e Ind., San José.

DZIEWONSKI, A., EKSTROM, G. \& SALGANIK, M. P., 1992: Centroidmoment tensor solutions for JulySeptember, 1991.- Phys. Earth Planet. Inter., 72: 1-11.

FAN, G., BECK, S. \& WALLACE, T., 1993: The seismic source parameters of the 1991 Costa Rica Aftershock sequence: Evidence for a transcurrent plate boundary.- Jour. Geophys. Res., 98: 15759-15778.

FENG, L., NEWMAN, A. V., PROTTI, M., GONZÁLEZ, V., JIANG, Y. \& DIXON,
T. H., 2012: Active deformation near the Nicoya Peninsula, northwestern Costa Rica, between 1996 and 2010: Interseismic megathrust coupling.- Jour. Geophys. Res. 117, DOI:10.1029/2012JB009230.

FERNÁNDEZ, M., 1995: Análisis sísmico en la parte central de Costa Rica y evaluación del hipotético sistema de falla transcurrente de Costa Rica.- 85 págs. + apéndices. Univ. Nac. Autón. de México, México D. F. [Tesis M.Sc.].

FERNÁNDEZ, M. \& PACHECO, J., 1998: Sismotectónica de la región central de Costa Rica.- Rev. Geol. Amér. Central, 21: 5-23.

FERNÁNDEZ, M. \& MONTERO, W., 2002: Fallamiento y sismicidad del área entre Cartago y San José, valle Central de Costa Rica.- Rev. Geol. Amér. Central, 26: 25-37.

FISHER, D. M., GARDNER, T. W., MARSHALL, J. \& MONTERO, W., 1994: Kinematics associated with the late Cenozoic deformation in Central Costa Rica: Western boundary of the Panama microplate.- Geology, 22: 263-266.

FISHER, D. M., GARDNER, T. W., MARSHALL, J., SAK, P. B. \& PROTTI, M., 1998: Effect of subducting seafloor roughness on forearc kinematics, Pacific Coast, Costa Rica.Geology, 26: 467-470.

GEOMATRIX CONSULTANTS, 1994: Informe final: acueducto de Orosi, sub-estudio de la vulnerabilidad sísmica de la conducción: El Llano a Tres Ríos, provincia de Cartago, Costa Rica.- 139 págs. Geomatrix Consultants Report, San Francisco [Informe Interno].

HENAR, J., MONTERO, W., DÍAZ, J. J., ALVAREZ, J. A., INSÚA, J. M. \& ROJAS, W., 2013: The Aguacaliente Fault, source 
of the Cartago 1910 earthquake (Costa Rica).- Terra Nova, 25: 368-373, DOI: 10.111/ter.12045.

KOLARSKY, R., MANN, P. \& MONTERO, W., 1995: Forearc deformation related to the subduction of the Cocos ridge, southeastern Costa Rica.- En MANN. P. (ed.):Geologic and Tectonic Development of the Caribbean Plate Boundary in Southern Central America.- Geol. Soc. Amer. Spec. Pap. 295: 235-262.

KRUSHENSKY, R. D., 1972: Geology of the Istarú Quadrangle, Costa Rica.- 46 págs. U.S. Geol. Surv. 1358.

LAFEMINA, P., DIXON, T.H., GOVERS, R., NORABUENA, E., TURNER, H., SABALLOS, A., MATTIOLI, G., PROTTI, M. \& STRAUCH, W., 2009: Fore-arc motion and Cocos Ridge collision in Central America.- Geochem. Geophys. Geosyst. 10(1), DOI:10.1029/2008GC002181.

LINKIMER, L., 2003: Neotectónica del extremo oriental del Cinturón Deformado del Centro de Costa Rica.- 103 págs. Univ. de Costa Rica, San José [Tesis Lic.].

LÓPEZ, A., 1999: Neo-and paleostress partitioning in the SW corner of the Caribbean plate and its fault reactivation potential.294 págs. Univ. of Tubingen, Germany [Thesis Ph.D].

MACMILLAN, I., GANS, P.B. \& ALVARADO, G., 2004: Middle Miocene to present plate tectonic history of the southern Central American Volcanic Arc.- Tectonophysics, 392: 325-348.

MARSHALL, J., FISHER, D.M. \& GARDNER, T.W., 2000: Central Costa Rica deformed belt: Kinematics of diffuse faulting across the western Panama block.Tectonics, 19: 468-492.
MARSHALL, J., IDLEMAN, B., GARDNER, T. \& FISHER, D., 2003: Landscape evolution within a retreating volcanic arc, Costa Rica, Central America.- Geology, 31: 419-422.

MCCLAY, K. \& DOOLEY, T., 1995: Analogue models of pull-apart-basins.- Geology, 8: 711-714.

MATUMOTO, T., LATHAM, G., OHTAKE, M., \& UMAÑA, J., 1977: Crustal structure in Southern Central America.- Bull Seism. Soc. Am., 67: 121-134.

MONTERO, C. \& GONZÁLEZ, V., 1990: Riesgo sísmico en Cartago: un análisis histórico espacial.- 157 págs. Univ. Nacional, Heredia [Tesis Lic.].

MONTERO, W., 1994: Neotectonics and related stress distribution in a subduction-collisional zone: Costa Rica.- Profil, 7: 125-141.

MONTERO, W., 2001: Neotectónica de la región central de Costa Rica: frontera oeste de la microplaca de Panamá.- Rev. Geol. Amér. Central, 24: 29-56.

MONTERO, W., 1994: Sismicidad y neotectónica.- En: DENYER, P. \& KUSSMAUL, S. (ed.): Atlas Geológico Gran Área Metropolitana.- Ed. Tecnológica de Costa Rica, Cartago: 147-160.

MONTERO, W., BARAHONA, M., ROJAS, W. \& TAYLOR, M., 2005: Los sistemas de falla Aguacaliente y Río Azul y relevos compresivos asociados, valle Central de Costa Rica.- Rev. Geol. Amér. Central, 33: 7-27.

MONTERO, W. \& DEWEY, J.W., 1982: Shallowfocus seismicity, composite focal mechanism, and tectonics of the Valle Central of Costa Rica.- Bull. Seismol. Soc. Amer., 72: 1611-1626. 
MONTERO, W. \& KRUSE, S., 2006: Neotectónica y geofísica de la falla Aguacaliente en los valles de Coris y del Guarco.- Rev. Geol. Amér. Central, 34/35: 43-58.

MONTERO, W., LEWIS, J., MARSHALL, J., KRUSE, S. \& WETMORE, P., 2013a: Neotectonic faulting and fore arc sliver motion along the Atirro-Río Sucio fault system, Costa Rica, Central America.- Geol. Soc. Amer. Bull. 125, DOI: 10.1130/B30471.1

MONTERO, W. \& ROJAS, W., 2014: Las fallas Purires y Picagres y su relación con la secuencia sísmica de Puriscal de 1990.- Rev. Geol. Amér. Central, 50: 36-69.

MONTERO, W., ROJAS, W. \& LINKIMER, L., 2013b: Neotectónica de las fallas Ochomogo y Capellades y su relación con el sistema de falla Aguacaliente, falda sur macizo Irazú-Turrialba, Costa Rica.- Rev. Geol. Amér. Central, 48: 119-139.

MONTERO, W., DENYER, P., BARQUERO, R., ALVARADO, G. E., COWAN, H., MACHETTE, M. N., HALLER, K. M. \& DART, R. L., 1998: Map and database of Quaternary faults and folds in Costa Rica and its offshore regions.- 63 págs. U.S. Geol. Surv. 98-481.

MORELL, K.D., KIRBY, E., FISHER, D.M. \& VAN SOEST, M., 2012: Geomorphic and exhumational response of the Central American Volcanic Arc to Cocos Ridge subduction.- Journ. Geophys, Res. 117, DOI:10.1029/2011JB008969.

PERALDO, G. \& MONTERO, W., 1994: Terremotos coloniales de Costa Rica.- 162 págs.- Ed. Tecnológica de Costa Rica, Cartago.

PERALDO, G. \& MONTERO, W., 1999: Sismología Histórica de América Central.347 págs. Inst. Panamericano de Geografía e Historia, México D. F.
PERALDO, G. \& MONTERO, W., 2010: Sismicidad anterior y posterior a los terremotos del 13 de abril y el 5 de mayo de 1910.- En: PERALDO, G. \& ACEVEDO, B. (eds.): Efemérides de la destrucción de Cartago cien años después (1910-2010).- Ed. Perro Azul, San José: 23-35.

OTTEMÖLLER, L., VOSS, P. \& HAVSKOV, J., 2011: SEISAN: the Earthquake Analysis Software for Windows, Solaris, LINUX, and MACOSX, version 9.0.1.- 361 págs. Univ. of Bergen, Bergen.

QUINTERO, R. \& GÜENDEL, F., 2000: Stress field in Costa Rica.- Journal. Seismology, 4: 297-319.

SALAZAR, L.G., OBANDO, L. \& MORA, R., 1992: Acueducto Metropolitano, tramo embalse El Llano-Río Navarro (Costa Rica): Un sitio bajo amenaza.- Rev. Geol. Amér. Central, 14: 85-96.

SCHAUFELBER，P. \& JIMÉNEZ, E., 1933: Algunas nociones sobre terremotos y temblores en Costa Rica.- 31 págs. Apuntes de Geología 7, Publ. Liceo de Costa Rica, No 15, Imprenta La Tribuna, San José.

SEGURA, G., BADILLA, E. \& OBANDO, L., 2011: Susceptibilidad al deslizamiento en el corredor Siquirres-Turrialba.- Rev. Geol. Amér. Central, 45: 101-121.

SNOKE, J. A., MUNSEY, J. W., TEAGUE, A. G. \& BOLLINGER, G. A. (1984). A program for focal mechanism determination by combined use of polarity and Sv-P amplitude ratio data.- Earthquake Notes, 55: 15-20.

SOJO, D., 2015: Modelo geológico del cuadrante Tapantí, Costa Rica.- 92 págs. Univ. de Costa Rica, San José [Tesis Lic.]. 
SUÁREZ, G., PARDO, M., DOMÍNGUEZ, J., PONCE, L., MONTERO, W., BOSCHINI, I. \& ROJAS, W., 1995: The Limón, Costa Rica earthquake of 22 April, 1991 $(\mathrm{Mw}=7.7)$ : Evidence of back-arc thrusting and collisional tectonics in a subduction environment.- Tectonics, 14: 518-530.

WELlS, S., BULLARD, T., MENGES, C., DRAKE, P., KARAS, K., KELSON, K., RITTER, J. \& WESLING, J., 1988:
Regional variations in tectonic geomorphology along a segmented convergent plate boundary, Pacific coast of Costa Rica.- Geomorphology, 1: 239-265.

WOODWARD \& CLYDE, 1993: A preliminary evaluation of earthquake and volcanic hazards significant to the major population centers of the Valle Central, Costa Rica.89 págs. Ret Corporation, San Francisco [Informe Interno]. 